\title{
Synthesis of Xenia diterpenoids and related metabolites isolated from marine organisms
}

\author{
Tatjana Huber ${ }^{\ddagger}$, Lara Weisheit ${ }^{\ddagger}$ and Thomas Magauer ${ }^{*}$
}

\author{
Review \\ Address: \\ Department of Chemistry and Pharmacy, \\ Ludwig-Maximilians-University Munich, Butenandtstraße 5-13, 81377 \\ Munich, Germany \\ Email: \\ Thomas Magauer ${ }^{*}$ - thomas.magauer@Imu.de \\ * Corresponding author $\ddagger$ Equal contributors \\ Keywords: \\ asymmetric synthesis; natural products; total synthesis; Xenia \\ diterpenoids; xenicanes
}

\author{
Beilstein J. Org. Chem. 2015, 11, 2521-2539. \\ doi:10.3762/bjoc. 11.273 \\ Received: 13 October 2015 \\ Accepted: 27 November 2015 \\ Published: 10 December 2015 \\ This article is part of the Thematic Series "Natural products in synthesis \\ and biosynthesis II". \\ Guest Editor: J. S. Dickschat \\ (c) 2015 Huber et al; licensee Beilstein-Institut. \\ License and terms: see end of document.
}

\begin{abstract}
This review describes strategies for the chemical synthesis of xenicane diterpenoids and structurally related metabolites. Selected members from the four different subclasses of the Xenia diterpenoid family, the xenicins, xeniolides, xeniaphyllanes and xeniaethers, are presented. The synthetic strategies are discussed with an emphasis on the individual key reactions for the construction of the uncommon nine-membered carbocycle which is the characteristic structural feature of these natural products. Additionally, the putative biosynthetic pathway of xenicanes is illustrated.
\end{abstract}

\section{Introduction}

Terpenoids are a large group of structurally diverse secondary metabolites. Among these natural products, Xenia diterpenoids or xenicanes represent a unique family with intriguing structural features and diverse biological activities. Many xenicanes display significant cytotoxic and antibacterial activity and are therefore of great interest for drug discovery, especially for their application as anticancer agents [1]. Marine soft corals of the genus Xenia (order Alcyonacea, family Xeniidae) are known to be rich in xenicane diterpenoids. The first reported member of these metabolites was xenicin (1), isolated from the soft coral Xenia elongata in Australia, whose structure was elu- cidated in 1977 by Schmitz and van der Helm (Figure 1a) [2]. The common numbering of the xenicane skeleton shown in Figure $1 \mathrm{~b}$ is used throughout this review.

Since then, several further xenicanes with various modifications of the cyclononane ring and isoprenyl side chain in their structure have been isolated. In general, the common structural feature of xenicanes is a bicyclic framework consisting of an A ring which is trans-fused to a nine-membered carbocyclic $\mathrm{B}$ ring. The family of Xenia diterpenoids was originally divided into three subfamilies: the xenicins (containing an 11-oxabi- 
a)

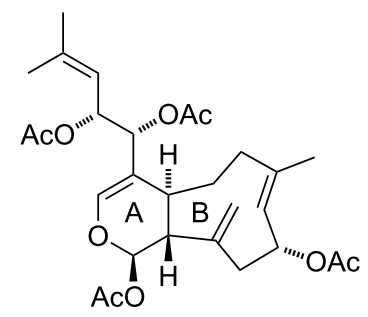

xenicin (1)

Figure 1: a) Structure of xenicin (1) and b) numbering of the xenicane skeleton according to Schmitz and van der Helm.

cyclo[7.4.0]tridecane ring system with an acetal functionality) [2], the xeniolides (containing an 11-oxabicyclo[7.4.0]tridecane ring system with a lactone functionality) [3] and the xeniaphyllanes (with a bicyclo[7.2.0]undecane ring system) [4] Later, an additional subfamily was discovered and named xeniaethers [5] (containing an 11-oxabicyclo[7.3.0]dodecane ring system). An overview of representative members of these subfamilies is depicted in Figure 2.

Xenicanes are closely related to a number of metabolites which also feature the characteristic cyclononene framework (Figure 3). For example, a class of bicyclic sesquiterpenes, caryophyllenes [21], exhibit the same bicyclo[7.2.0]undecane skeleton as xeniaphyllanes. Furthermore, while monocyclic azamilides [22] are seco-A-ring diterpenoids that are acylated with fatty acids, Dictyota diterpenes [23,24] either bear a similar seco-ring fragment, as observed for dictyodiol (24), or comprise a fused $\gamma$-butyrolactone moiety, as in dictyolactone (25, Figure 3).

This review intends to provide a comprehensive overview of research covering xenicane diterpenoids and related natural products. In the following section, we present a biosynthetic proposal, discuss various synthetic approaches towards xenicane diterpenoids and highlight successful total syntheses.

\section{Review}

\section{Biosynthetic hypothesis}

The proposed biogenesis of xenicanes (Scheme 1) is suggested to be similar to the reported biosynthesis of the structurally related caryophyllene sesquiterpenes [25]. Xenia diterpenoids are believed to originate from the common diterpenoid precursor geranylgeranyl pyrophosphate (GGPP, 28), which is assembled from the two terpene units, isoprenyl pyrophosphate (IPP, 26) and dimethylallyl pyrophosphate (DMAPP, 27) [26] Initial loss of a diphosphate anion from GGPP generates an allylic cation in $\mathbf{2 9}$ which is intramolecularly trapped by nucleo- philic attack of the $\mathrm{C} 3, \mathrm{C} 10$-double bond, forming the secondary cation 30. Attack of the newly generated C1,C2-double bond with simultaneous loss of a proton then affords the bicyclo[7.2.0] undecane ring system $\mathbf{3 1}$ as found in xeniaphyllanes [3]. Finally, double $\mathrm{C}-\mathrm{H}$ oxidation furnishes the $\beta$-hydroxy aldehyde $\mathbf{3 2}$ which can undergo a retro-aldol reaction with concomitant opening of the cyclobutane ring to form dialdehyde $\mathbf{3 3}$ as the common biogenetic precursor of xenicins, xeniolides and xeniaethers.

An alternative biosynthetic pathway proposed by Schmitz and van der Helm involves the direct formation of the ninemembered carbocyclic ring via oxidative cyclization of geranyllinalool (34) [2], which is formed from GGPP (28) by enzymatic hydrolysis of the pyrophosphate unit and allylic rearrangement (Scheme 2).

\section{Synthetic strategies}

The unusual molecular structures and the potential of xenicanes to act as chemotherapeutic agents make these natural products attractive targets for synthetic chemists. Although more than 100 different Xenia diterpenoids are known to date, only a few total syntheses of xeniolides have been reported in the last two decades. Surprisingly, since the discovery of xenicin in 1977 [2], no total synthesis of a member of this subclass has been accomplished.

The synthesis of nine-membered rings is challenging, especially when they contain an $E$-configured double bond. Different strategies for the construction of $E$ - or $Z$-cyclononenes have been reported to date and common reactions are summarized in Scheme 3. Transition metal-catalyzed ( $[\mathrm{M}]=\mathrm{Ru}, \mathrm{Mo}, \mathrm{W})$ ringclosing metathesis (RCM) reactions of 1,10-dienes $\mathbf{A}$ can be employed for the synthesis of cyclononenes. The $E / Z$-selectivity of the olefin depends on the ring-size and the choice of catalyst. As a consequence of avoiding ring strain, small- and medium-sized rings are generally obtained with $Z$-configuration of the alkene. The Grob fragmentation reaction of fused 6,5-bicycles $\mathbf{B}$ is usually a concerted process that affords cyclononenes in a stereospecific manner [27]. The relative configuration of the leaving group ( $\mathrm{LG}=\mathrm{OTs}$, OMs, $\mathrm{Hal}, \mathrm{NR}_{3}{ }^{+}$) and the adjacent substituent determine the $E / Z$-geometry of the olefin. A cis-geometry leads to the formation of the $E$-configured double bond. In general, the Grob fragmentation is the most commonly employed method for the synthesis of cyclononenes due to the predictability of the stereochemical outcome of the product. The construction of cyclononenes can furthermore be achieved by thermal [3,3]-sigmatropic rearrangements of 1,5-dienes $\mathbf{C}$. When the reaction proceeds via a chairlike transition state, the substituents are oriented with minimal steric hindrance to give the $E, E$-configured nine- 


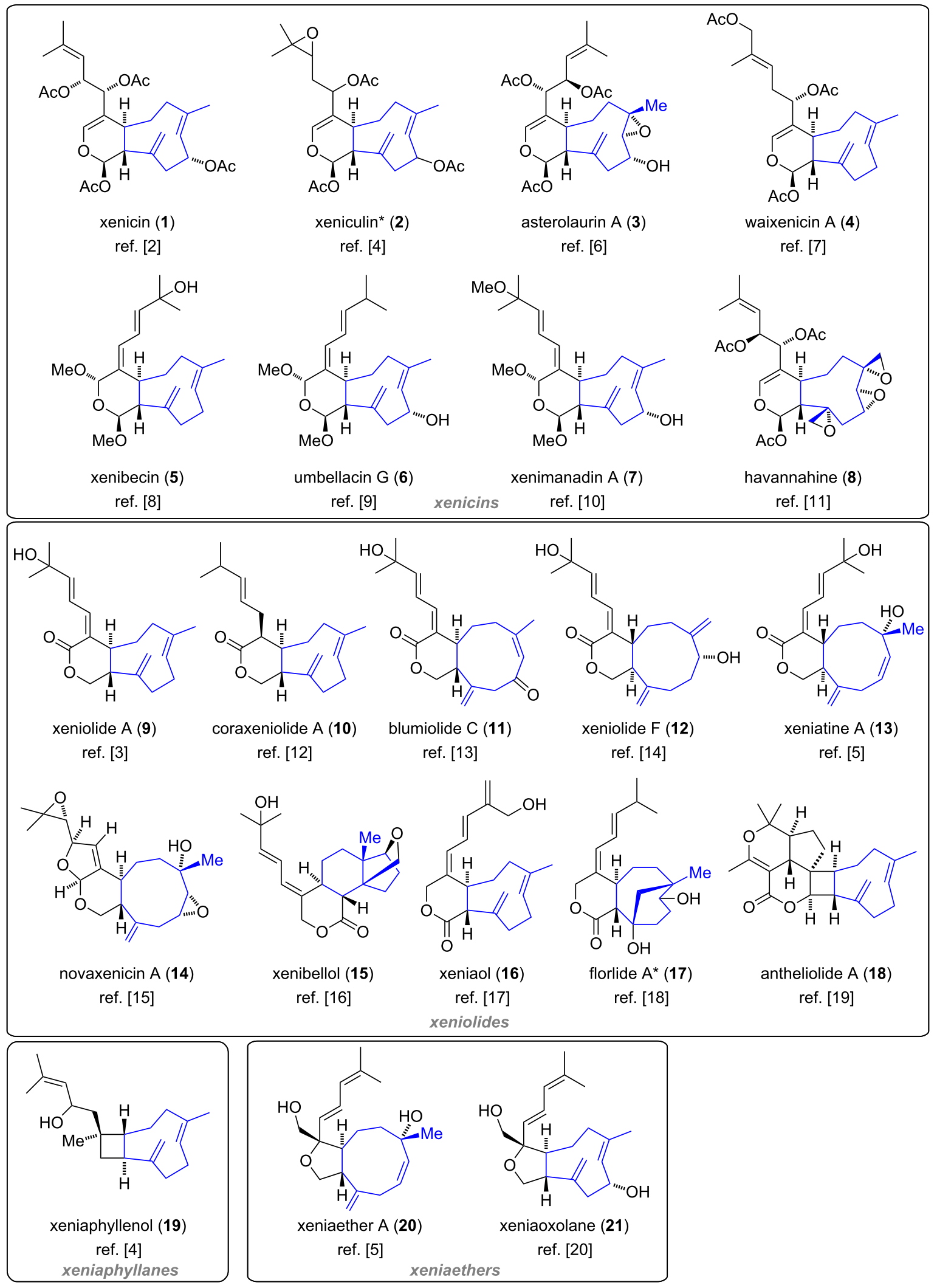

Figure 2: Overview of selected Xenia diterpenoids according to the four subclasses [2-20]. The nine-membered carbocyclic rings are highlighted in blue. * Stereochemistry not determined. 

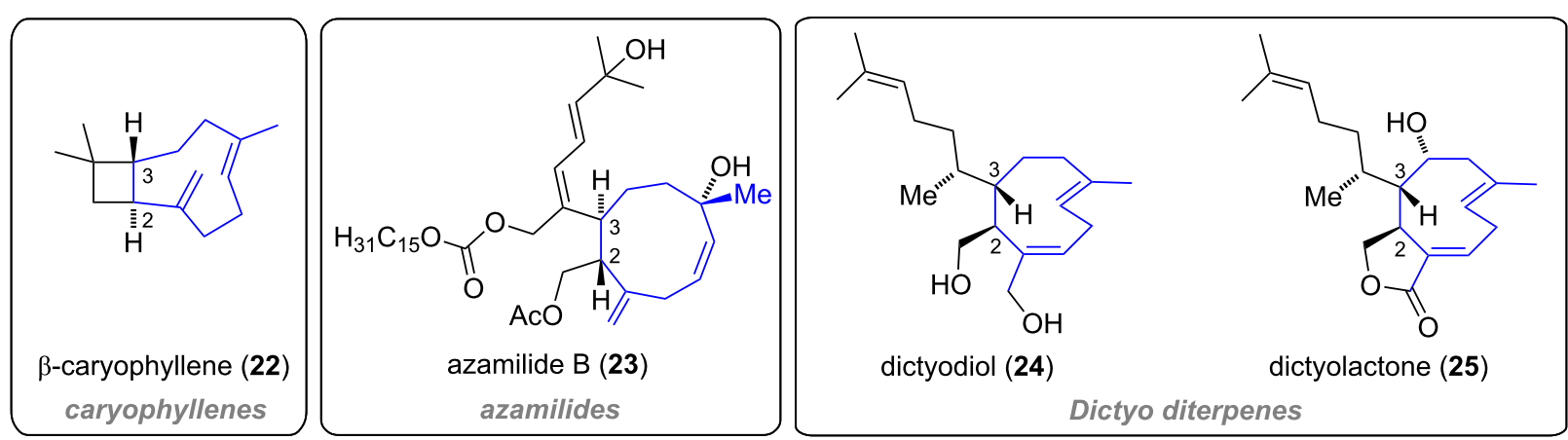

Figure 3: Representative members of the caryophyllenes, azamilides and Dictyota diterpenes.

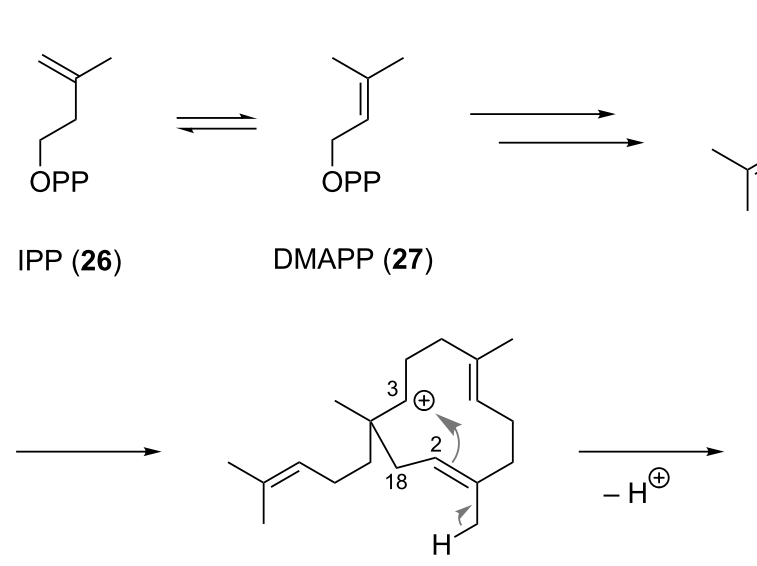

30
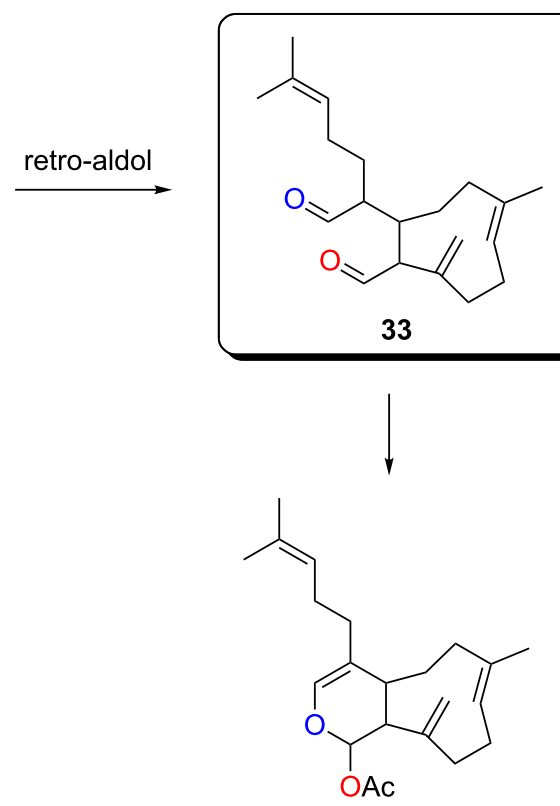

xenicins

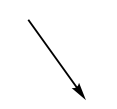<smiles>CC=C(C)CCC=C(C)CC[C@@H](C=C(C)C)[C@H](CC=C(C)C)OP</smiles>

GGPP (28)<smiles>CC(C)=CCC=C(C)CC=C(C)CC=C(C)CCC=C(C)C</smiles>

29<smiles>C=C1CCC2=C(C)CCC(C(C)C)[C@@H]2C1(C)CCC=C(C)C</smiles>

31

xeniaphyllanes<smiles>C=C1CCC(=C)C(CCC(C)=CCC=C(C)C)C1</smiles>

32

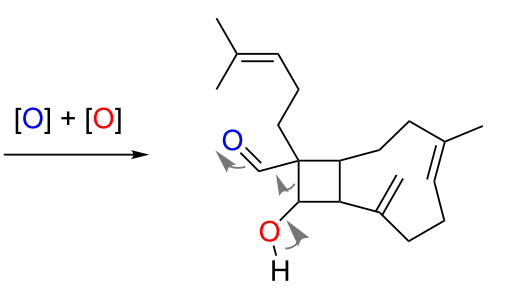<smiles>C=C1CCC(=C(C)CCC2C(=C)COC(=O)C2=CCC=C(C)C)C1</smiles>

xeniolides<smiles>C=C(C)/C=C/C1C(=C)CCC1CC=CC(C)=CC</smiles>

xeniaethers

Scheme 1: Proposed biosynthesis of Xenia diterpenoids (OPP = pyrophosphate, GGPP = geranylgeranyl pyrophosphate, IPP = isoprenyl pyrophosphate, DMAPP = dimethylallyl pyrophosphate). 


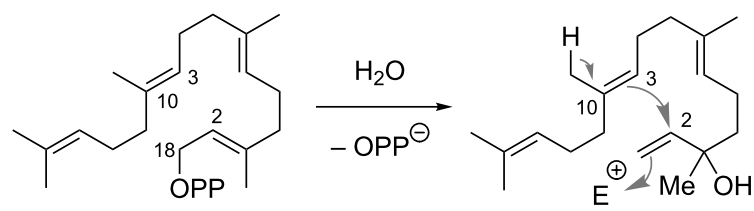

GGPP (28) geranyllinalool (34)

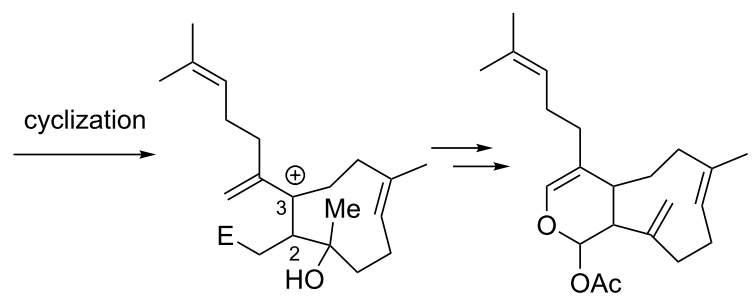

35

Scheme 2: Direct synthesis of the nine-membered carbocycle as proposed by Schmitz and van der Helm (E = electrophilic oxygen species) [2].

membered ring. Ring contraction reactions of 13-membered lactams afford cyclononenes via intramolecular acyl transfer reactions. The configuration of the double bond derives from precursor $\mathbf{D}$ and thus allows the formation of $E$ - or $Z$-configured cyclononenes. Additionally, the intramolecular palladiumcatalyzed cyclization of haloalkenes with organoboranes affords cyclononenes with retention of the double bond configuration [28]. The corresponding allylic alcohols can be prepared by a Nozaki-Hiyama-Kishi coupling of haloalkenes with aldehydes.

The first synthesis of the unusual nine-membered carbocyclic ring was reported by Corey for the total synthesis of $\beta$-caryophyllene in 1963 (Scheme 4) [29-31]. Starting with a photochemical $[2+2]$ cycloaddition between 2-cyclohexen-1-one (37) and isobutene (36), an isomeric mixture of trans- and cisfused [4.2.0]octanone was obtained (trans-38/cis-39=4:1). The more stable cis-bicycle 39 could be obtained by isomerization of trans-38 with base. Acylation with sodium hydride and dimethyl carbonate followed by methylation furnished $\beta$-keto ester 40. Addition of lithium acetylide $\mathbf{4 1}$ to the keto group led to acetal 42. Hydrogenation of the triple bond under basic

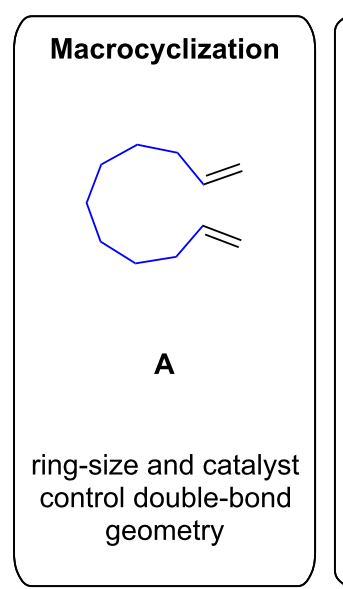

$[\mathrm{M}]$

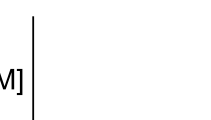

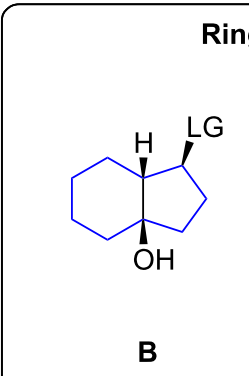

Fragmentation

relative orientation of $\mathrm{H}$ and leaving-group (LG) control doublebond geometry

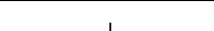

\section{Ring Expansion}<smiles>C=C[C@H]1CCC[C@@H]1C=C</smiles>

C

Electrocyclization

relative orientation of substituents controls double-bond geometry

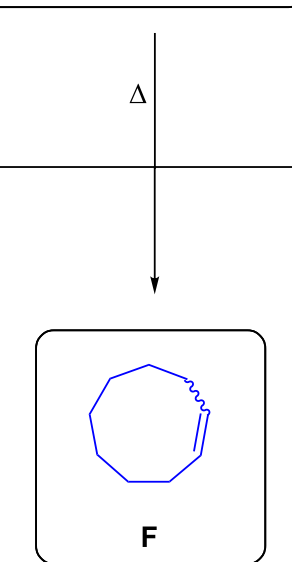

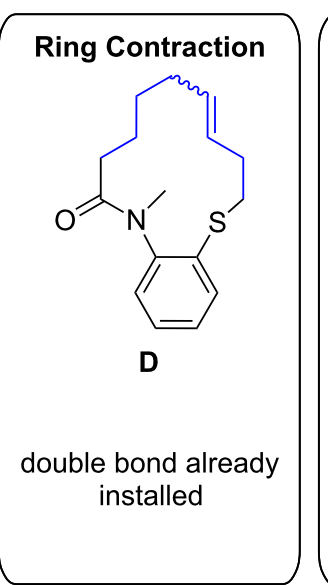

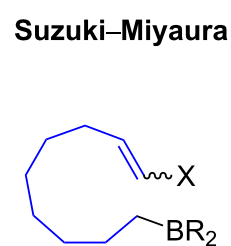

E

retention of double bond configuration

1. [O]

2. base 


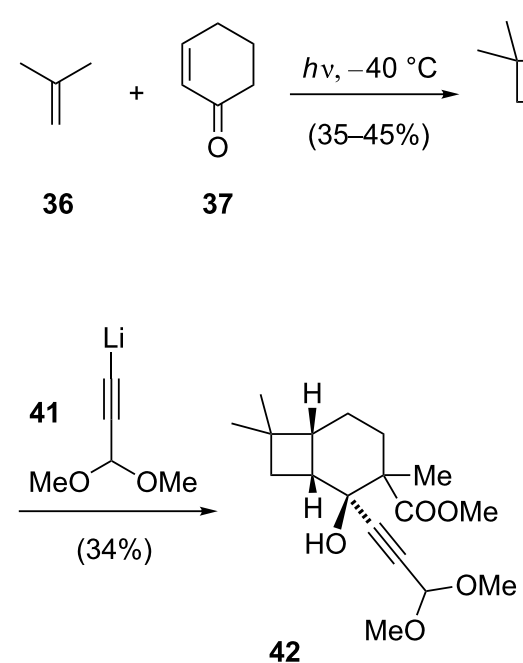

42

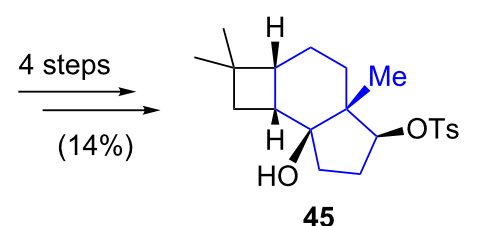

45

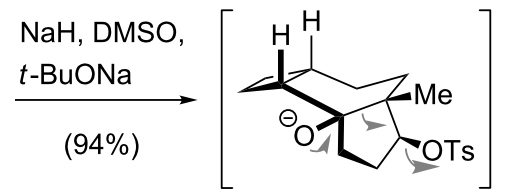

46
38

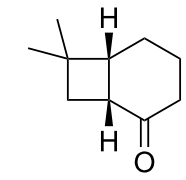

39
$\mathrm{KOH}, \mathrm{MeOH}$

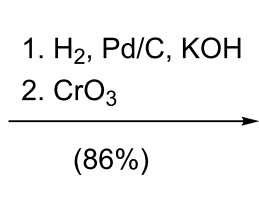

$\underbrace{C M e}_{43}$

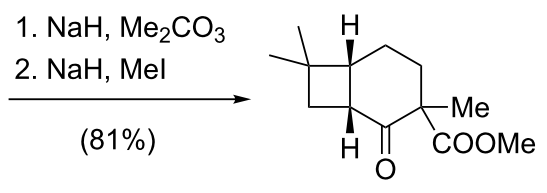

40

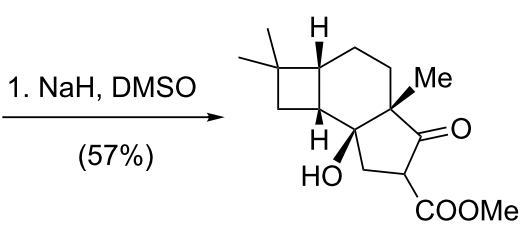

44

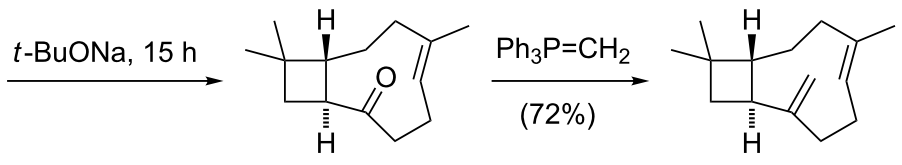

48

$\beta$-caryophyllene (22)

Scheme 4: Total synthesis of racemic $\beta$-caryophyllene (22) by Corey.

conditions resulted in cleavage of the acetal and ring closure to the corresponding lactol which was oxidized with chromic acid to furnish $\gamma$-lactone 43. An ensuing Dieckmann condensation [32] of $\mathbf{4 3}$ afforded a 4,6,5-tricycle which was converted to the fragmentation precursor $\mathbf{4 5}$ in four further steps. A base-mediated Wharton-type Grob fragmentation [33] then served as the key step to construct the cyclononene motif of bicycle 47 . Prolonged exposure of the resulting cis-fused 4,9-bicycle 47 to sodium tert-butoxide gave rise to the epimerized trans-isomer 48. Finally, the exocyclic double bond was introduced by olefination of ketone 48 and thus completed the racemic total synthesis of $\beta$-caryophyllene (22) in 13 steps. This elegant synthesis received considerable attention and revealed already at that time the great potential of modern synthetic organic chemistry.

More than 20 years later, in 1984, Oishi and co-workers reported a different strategy which culminated in the total syn- thesis of racemic $\beta$-caryophyllene (22) (Scheme 5) [34]. Their synthesis commenced with conjugate addition of ethyl (phenylsulfonyl)acetate, a methylsulfonyl anion equivalent, to cyclobutene ester $\mathbf{4 9}$ followed by a sequence consisting of saponification, regioselective decarboxylation and reesterification to afford methyl ester 50. The ester group was reduced with lithium aluminum hydride and the resulting alcohol was converted to the corresponding silyl ether. Next, alkylation of the metalated sulfone with allylic chloride $\mathbf{5 1}$ afforded alcohol 52 after desilylation. Subsequent desulfonylation with sodium amalgam and Jones oxidation of the primary alcohol furnished carboxylic acid $\mathbf{5 3}$. The corresponding tertiary amide was then formed by sequential reaction of carboxylic acid $\mathbf{5 3}$ with oxalyl chloride and $\mathrm{N}$-methylaniline derivative 54. The following twostep debenzylation sequence afforded alcohol 55 which was converted to the corresponding mesylate, serving as a key intermediate for the construction of the nine-membered carbocyclic ring. Treatment of this intermediate with potassium tert- 


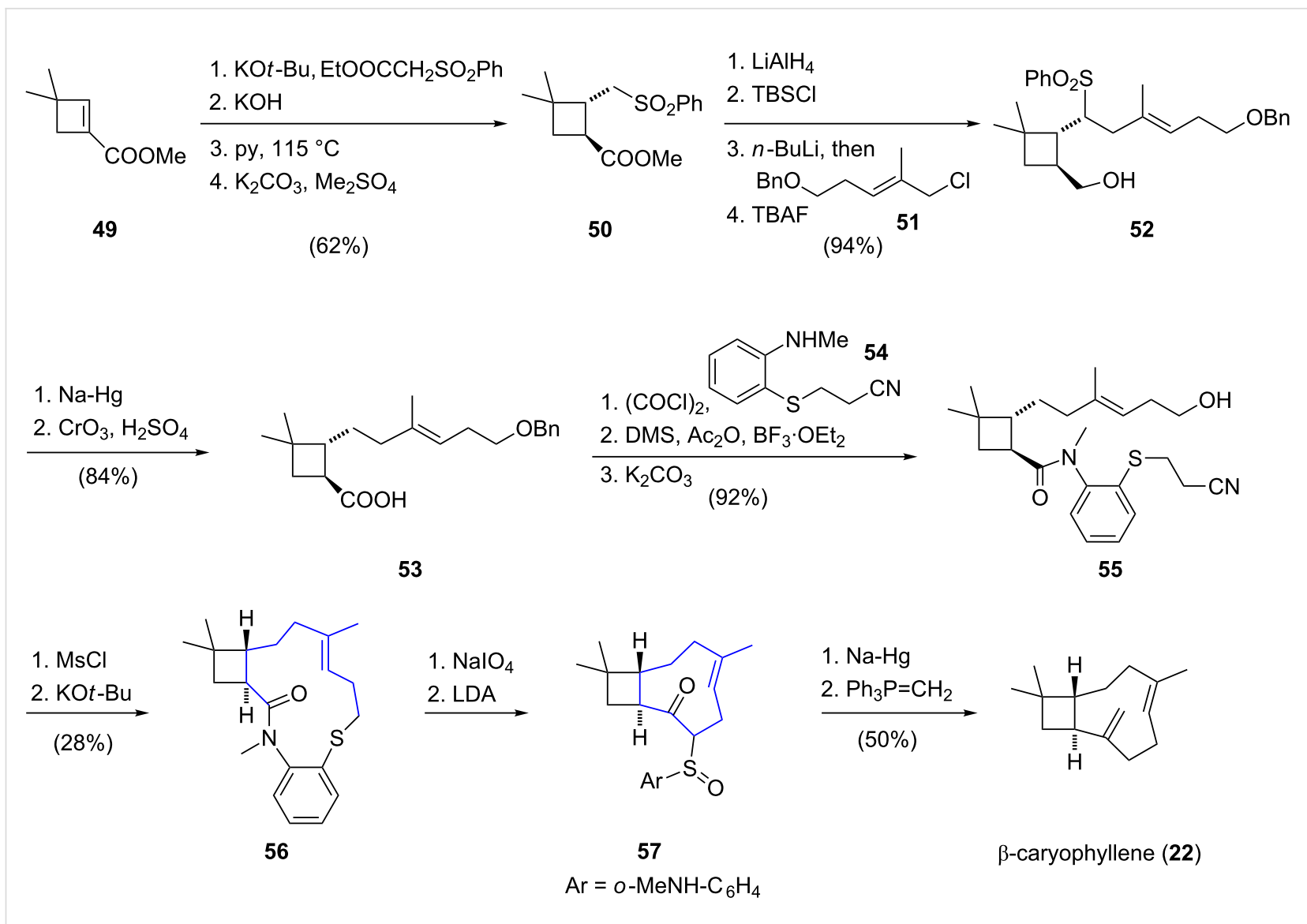

Scheme 5: Total synthesis of racemic $\beta$-caryophyllene (22) by Oishi.

butoxide led to the cleavage of the 2-cyanoethylsulfide moiety and the generation of a thiolate anion, which underwent $\mathrm{S}_{\mathrm{N}} 2$ displacement of the primary mesylate, affording the 13-membered lactam 56. The stage was now set for the key intramolecular acyl transfer reaction to form the cyclononene motif. After sodium periodate oxidation of sulfide $\mathbf{5 6}$ to the corresponding sulfoxide, addition of lithium diisopropylamide initiated the intramolecular acyl transfer and led to formation of cyclononene $\mathbf{5 7}$ in quantitative yield. Reductive desulfonylation and a final Wittig olefination of the ketone then afforded racemic $\beta$-caryophyllene (22). In summary, the total synthesis of $\beta$-caryophyllene was achieved in 19 steps with an overall yield of $6.3 \%$. Although the key intramolecular acyl transfer reaction for construction of the cyclononene ring could be realized in quantitative yield, the low-yielding formation of the macrocyclic thioether reduced the overall efficiency of the presented synthetic route. Based on a similar strategy and using the corresponding $Z$-isomer of cyclization precursor 39, Oishi and co-workers reported a total synthesis of racemic isocaryophyllene, the cis double bond isomer of caryophyllene. Further total syntheses of isocaryophyllene have also been reported by Kumar [35,36], Miller [37] and Bertrand [38].
In 1995, Pfander reported the synthesis of an important building block [24] for the total synthesis of coraxeniolide A (10) [12], starting from chiral (-)-Hajos-Parrish diketone (58) [39]. Based on Pfander's seminal work, the first total synthesis of a xenicane diterpenoid was then accomplished by Leumann in 2000 (Scheme 6) [40]. Starting from enantiopure (-)-Hajos-Parrish diketone (58), allylic alcohol 59 was prepared by regioselective reduction of the carbonyl group, silylation of the resulting alcohol and further reduction of the enone moiety. An ensuing transetherification of alcohol $\mathbf{5 9}$ with ethyl vinyl ether gave an allyl vinyl ether, which underwent a magnesium perchloratepromoted [1,3]-sigmatropic rearrangement [41] to afford an aldehyde that was converted to dimethylacetal 60. The following epoxidation proceeded with good stereoselectivity $(\alpha / \beta \approx 11: 1)$ and the regioselective opening of the epoxide moiety using lithium cyanide afforded a $\beta$-hydroxy nitrile in a trans-diaxial arrangement. Under basic conditions, the configuration of the nitrile group at $\mathrm{C} 2$ was inverted, furnishing the thermodynamically more stable $\mathbf{6 1}$. Nitrile $\mathbf{6 1}$ was then converted to lactol 62 in seven further steps. Next, the cyclononene ring of 63 was constructed via a Grob fragmentation of 6,6,5-tricycle $\mathbf{6 2}$, affording the bicyclic product $\mathbf{6 3}$ in very good yield, 


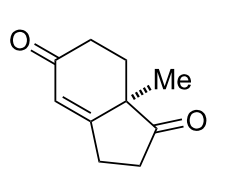

58

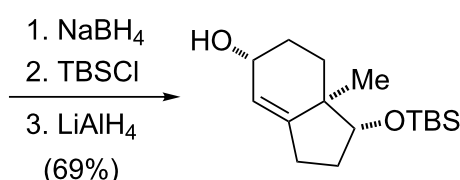

59

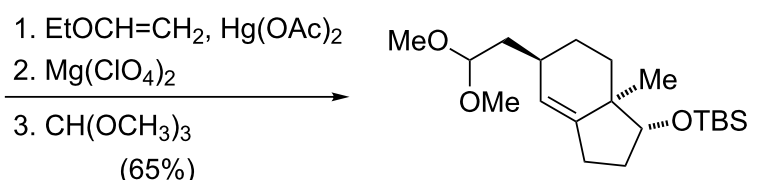

$(65 \%)$

60

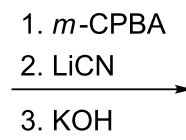

(46\%)<smiles>CNCC1C(CC(C)OC)CCC2(C)C(O[13CH3])CCC12O</smiles>

61

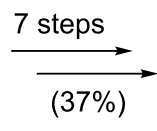

$(37 \%)$<smiles>C[C@]1([O-])CCCC2(O)[C@H]3COC(O)CC3CCC21O</smiles>

62

LDA, then<smiles></smiles>

63
1. TBSCl

2. Tebbe reagent

3. TBAF

4. $\mathrm{Ag}_{2} \mathrm{CO}_{3}$

(52\%)<smiles></smiles>

64

\section{NaDMSO \\ $(88 \%)$}

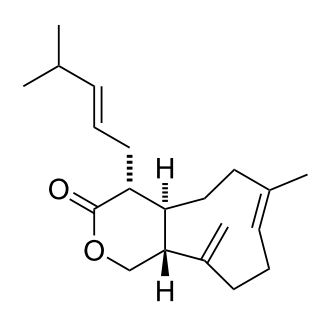

TBD

$(80 \%)$ 10-epi-coraxeniolide A (65)

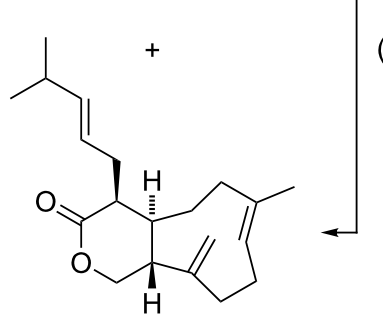

coraxeniolide A (10)

Scheme 6: Total synthesis of coraxeniolide A (10) by Leumann.

however, as a mixture of lactol epimers $(\alpha / \beta \approx 56: 44)$. Silyl protection of the lactol and subsequent Tebbe olefination [42] of the ketone group installed the exocyclic double bond of the nine-membered carbocycle. Desilylation followed by oxidation with silver carbonate then afforded lactone 64. For the introduction of the side chain, the enolate derived from lactone $\mathbf{6 4}$ was treated with 1-bromo-4-methylpent-2-ene, giving a 1:6 mixture of coraxeniolide A (10) and its epimer 65. By equilibration with triazabicyclodecene (TBD), the ratio of $\mathbf{1 0 : 6 5}$ could be inverted to $3: 1$. In summary, coraxeniolide A (10) was synthesized in a longest linear sequence of 23 steps with an overall yield of $1.4 \%$.

The most complex xenicane diterpenoid synthesized to date is pentacyclic antheliolide A (18) [18] by Corey (Scheme 7) [43]. The linear precursor 68 was prepared from vinyl bromide 66 and aldehyde $\mathbf{6 7}$ in six steps in $34 \%$ yield. After saponification of the ester functionality, treatment with tosyl chloride and trimethylamine resulted in the formation of a ketene that underwent a diastereoselective intramolecular [2+2] cycloaddition to provide bicyclic ketone 69. Addition of TMS cerium acetylide to the carbonyl group of $\mathbf{6 9}$, followed by desilylation under basic conditions gave rise to $( \pm)$-ethynylcarbinol, which was separated by chiral HPLC. The desired diastereomer was then transformed to benzene sulfinate ester 70. A palladiumcatalyzed [2,3]-sigmatropic rearrangement formed an isomeric allenic sulfone [44] which, upon conjugate addition of diethyl amine followed by hydrolysis afforded a $\beta$-ketosulfone. For the following ring closure, the primary alcohol was desilylated and converted to the corresponding allylic carbonate 71 . The cyclononene structure $\mathbf{7 2}$ was then assembled via a palladiumcatalyzed and base-mediated cyclization of carbonate 71 [45]. Reductive cleavage of the sulfone using aluminium amalgam afforded a ketone, which was converted to an exocyclic double bond by treatment with Tebbe's reagent [42]. In order to convert the methoxy acetal to the corresponding lactone, 
<smiles>C=C(Br)CCC=C(C)C</smiles>

67

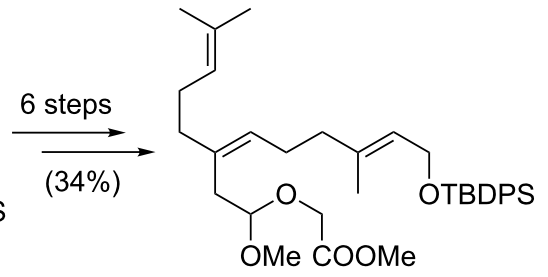

68<smiles>COC(=O)OC/C=C(\C)CC[C@H]1C(=O)[C@@H]2OC(OC)C[C@]12CCC=C(C)C</smiles>

69

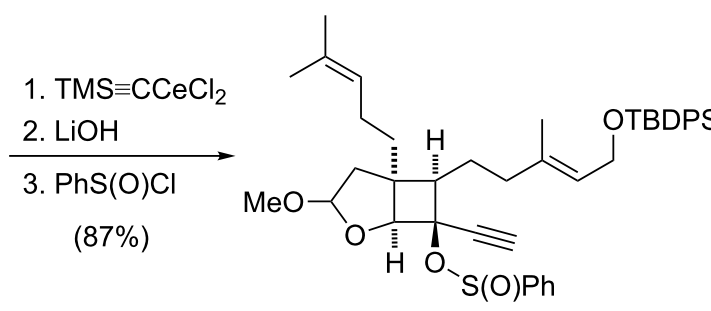

70

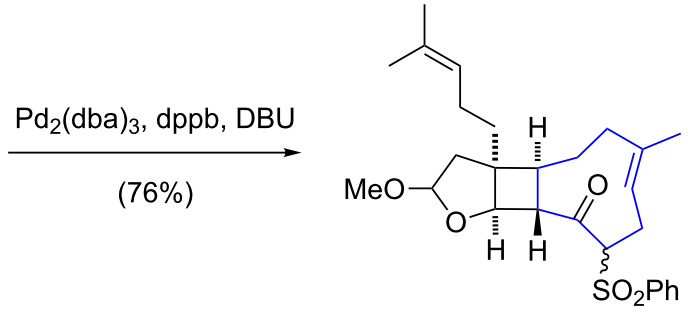

72
1. $P d_{2}(d b a)_{3}$

2. $\mathrm{Et}_{2} \mathrm{NH}$, then $\mathrm{HCl}$

3. py.HF

4. $\mathrm{MeOC}(\mathrm{O}) \mathrm{Cl}$

$(70 \%)$

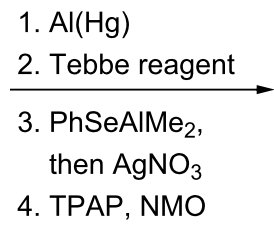

$(41 \%)$<smiles>COC(=O)OC/C=C(\C)CC[C@H]1[C@H](C(=O)CS(=O)(=O)c2ccccc2)[C@H]2OC(OC)C[C@@]12CCC=C(C)C</smiles>

71

73

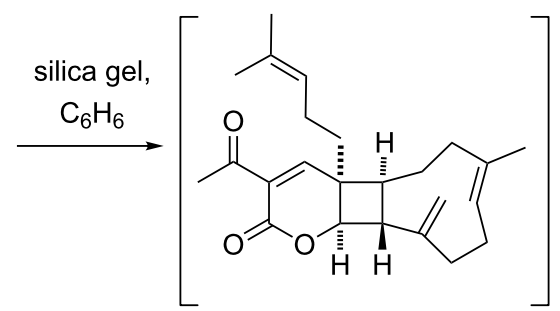

76

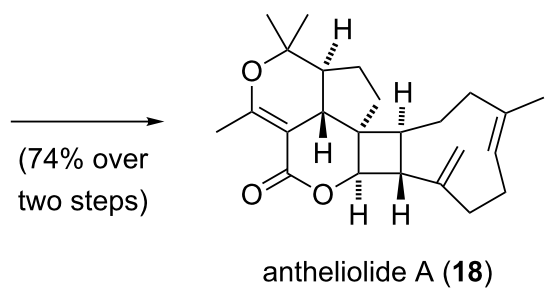

Scheme 7: Total synthesis of antheliolide A (18) by Corey.

without affecting the sensitive caryophyllene-like subunit, the methoxy group was replaced with a phenylseleno moiety, which was converted to the alcohol and finally oxidized to lactone $\mathbf{7 3}$. In three further steps, lactone $\mathbf{7 3}$ was converted to aldehyde ester 74, which upon treatment with piperidine gave a $\beta$-enamino ester 75. Finally, an elegant cascade reaction involving an aldol condensation, followed by a hetereo
Diels-Alder reaction closed the last three rings and antheliolide A (18) was obtained in $74 \%$ yield. In summary, the successful total synthesis of antheliolide A proceeded in 25 linear steps with an overall yield of $1.7 \%$.

The total syntheses of coraxeniolide A (10) and $\beta$-caryophyllene (22) reported by Corey [46] in 2008 are based on Pfander's 
idea [24] to construct the cyclononene fragment from (-)-Hajos-Parrish diketone (58) [39] (Scheme 8). Chiral hydroxy dione 77 was synthesized according to a literatureknown procedure [47]. Regioselective reduction with sodium borohydride, followed by dehydration under Mitsunobu conditions and silylation of the tertiary alcohol furnished trimethylsiloxy ketone 78. The ketone functionality was then diastereoselectively reduced under Corey-Bakshi-Shibata conditions [48] and an ensuing desilylation furnished a diol. In order to introduce a leaving group for the following key step, the secondary hydroxy group was tosylated to afford 79. Once again, a stereospecific Grob fragmentation of tosylate $\mathbf{7 9}$ served as the key step for the synthesis of the enantiomerically pure and configurationally stable nine-membered $E, Z$-dienone $\mathbf{8 0}$. The synthesis of the enantiomer of dienone $\mathbf{8 0}$, ent-80, was accomplished by a route parallel to that presented in Scheme $8 \mathrm{a}$, starting from ent-77. The highly efficient construction of these versatile intermediates provides a basis to synthesize a variety of natural products containing this macrocyclic structural motif. Based on chiral enone 80 and its enantiomer, ent-80, coraxeniolide A (10) and $\beta$-caryophyllene (22) were synthesized in five and four further steps, respectively. The synthesis of $\mathbf{1 0}$ continued with a trityl perchlorate-catalyzed conjugate addition of silyl ketene acetal 81a to enone ent-80. Deprotonation and trapping of the resulting enolate with formaldehyde furnished lactone $\mathbf{8 2}$ in a regio- and stereoselective fashion. Introduction of the exocyclic double bond proved to be challenging and therefore salt-free, highly reactive methylenetriphenylphosphorane was used. Finally, $\alpha$-alkylation of the lactone with iodide $\mathbf{8 3}$ provided coraxeniolide A (10) and its epimer in a 1:6 ratio which could be reversed to $4: 1$ by base-mediated equilibration. Purification by column chromatography, allowed the two epimers to be separated and afforded coraxeniolide A (10) in 38\% yield over three steps.

Additionally, the enantioselective total synthesis of $\beta$-caryophyllene was realized starting from key intermediate 80 . The route commenced with conjugate addition of silyl ketene acetal $\mathbf{8 1 b}$ to enone $\mathbf{8 0}$ from the sterically less hindered re-face. The ester group was selectively reduced and desilylation afforded alcohol 84. The generated primary alcohol was tosylated and regioselective deprotonation followed by intramolecular $\alpha$-alkylation stereoselectively formed the cyclobutane ring. A final Wittig methylenation introduced the exocyclic double bond and afforded (-)- $\beta$-caryophyllene (22), for the first time in an enantioselective manner. In conclusion, Corey's protocol for a)<smiles>CC12CCC(=O)CC1(O)CCC2=O</smiles>

77

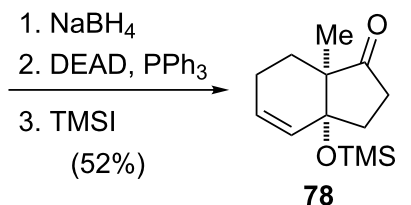

78

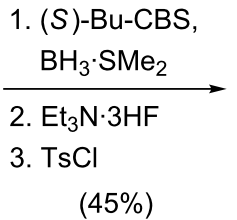

(45\%)<smiles>CC1CCC2(O)C([O-])CCCC12C</smiles>

79

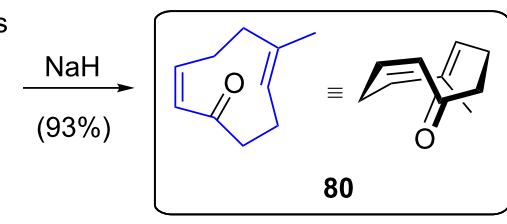

b)<smiles>CCCC1C=CC=CC1=O</smiles>

ent-80
1. $\mathrm{Ph}_{3} \mathrm{CClO}_{4}$

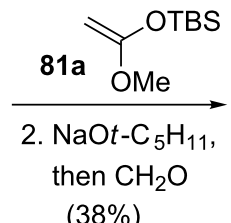

$(38 \%)$<smiles>CC1=CCC(=O)[C@H]2COC(=O)C[C@H]2C1</smiles>

82

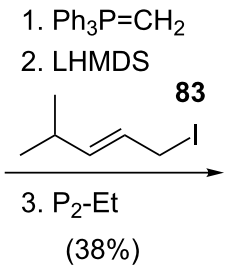

(38\%)<smiles>C=C1CCC(=C(C)CCC2C(C)COC(=O)[C@@H]2CCC=C(C)C)C1</smiles>

coraxeniolide A (10)<smiles>CCPN(C)P(=N[PH](C)(C)C)(N(C)C)N(C)C</smiles>

$\mathrm{P}_{2}$-Et c)

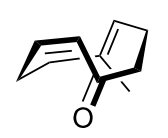

80<smiles>COC(O[Na])=C(C)C</smiles>
$\mathrm{Ph}_{3} \mathrm{CClO}_{4}$, then DIBAL, then $\mathrm{Et}_{3} \mathrm{~N} \cdot 3 \mathrm{HF}$

(84\%)

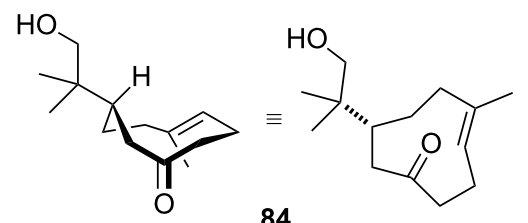

84

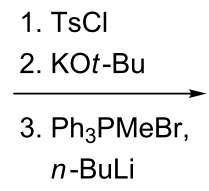

(48\%)

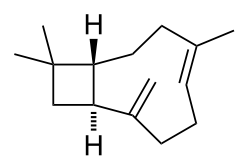

$\beta$-caryophyllene (22) 
the synthesis of a highly versatile building block represents a valuable platform for the construction of many different metabolites containing the nine-membered carbocyclic ring segment. The application of this useful intermediate was elegantly demonstrated in the synthesis of coraxeniolide A proceeding in $14 \%$ yield over five steps.

Altmann and co-workers disclosed the total synthesis of blumiolide C (11) [20] employing a $Z$-selective ring-closing metathesis reaction for construction of the cyclononene unit [49]. The synthesis started with a diastereoselective Evans synaldol reaction between substituted propanal 86 and $E$-crotonyloxazolidinone 85 (Scheme 9). The resulting secondary alcohol was silylated and the chiral auxiliary was cleaved with lithium borohydride. Acylation with acryloyl chloride gave ester 87 and a ring-closing metathesis reaction using Grubbs second generation catalyst [50] furnished an $\alpha, \beta$-unsaturated lactone. Subsequent 1,4-addition of the cuprate derived from alkylmagnesium chloride $\mathbf{8 8}$ provided the trans-product with excellent diastereoselectivity and thus installed the required stereocenter at the $\mathrm{C} 3$ position of the natural product. After deprotection of the sterically less hindered silyl ether, the resultant primary alcohol was oxidized to give aldehyde 89. By treatment with in situ generated divinylzinc, aldehyde $\mathbf{8 9}$ was transformed to an allylic alcohol which was converted to the corresponding paramethoxybenzyl ether 90 using Bundle's reagent [51]. In the key step of the synthesis, the nine-membered carbocyclic ring was constructed via a ring-closing metathesis reaction. Under optimized conditions, Hoveyda-Grubbs second generation catalyst [52] selectively converted diene $\mathbf{9 0}$ to the bicyclic ring system 91 in $66 \%$ yield. For the installation of the exocyclic double bond, bicycle 92 was treated with Martin sulfurane [53]. Subsequent hydrolysis of the acetal functionality and oxidation of the resulting lactol restored the lactone function in bicycle 93. The side chain of blumiolide $\mathrm{C}$ was introduced by an aldol reaction between lactone $\mathbf{9 3}$ and aldehyde $\mathbf{9 4}$. In the final sequence, blumiolide C (11) was obtained via stereospecific dehydration, removal of the para-methoxybenzyl ether and oxidation. In summary, the total synthesis of blumiolide $\mathrm{C}$ was accomplished in an overall yield of $0.63 \%$.

In 2005, Hiersemann and co-workers reported an approach towards the synthesis of xeniolide F [13] employing a catalytic asymmetric Claisen rearrangement to set the crucial stereocen-<smiles>C/C=C/C(=O)N1C(=O)OCC1Br</smiles>

86

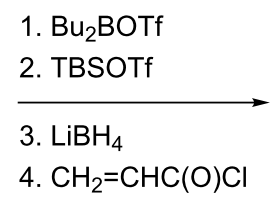

$(51 \%)$<smiles>C=CC(=O)OC[C@@H](C=C)C(CO[SbH3])O[SbH3]</smiles>

87

1. Grubbs II

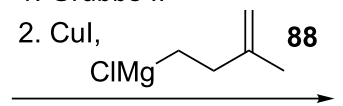

3. CSA

4. DMSO, $(\mathrm{COCl})_{2}, \mathrm{NEt}_{3}$ $(69 \%)$<smiles>C=C(C)CC[C@H]1CC(=O)OC[C@H]1C(C=O)C[R5](=O)(=O)c1ccccc1</smiles>

89

1. $\mathrm{CH}_{2}=\mathrm{CHMgCl}, \mathrm{ZnCl}_{2}$

2. $\mathrm{PMBOC}(=\mathrm{NH}) \mathrm{CCl}_{3}$, PPTS

(42\%)

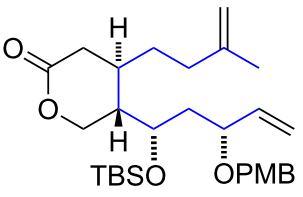

$\stackrel{\text { Hoveyda-Grubbs II }}{\longrightarrow}$

$(66 \%)$

90

1. Martin sulfurane<smiles>[R16]OC1/C=C(\C)CCC2CC(OC)OC[C@@H](C2)[C@@](C)(O)C1</smiles>

2. aq HF

3. TPAP, NMO

$(63 \%)$<smiles>[R16]O[C@H]1C=C(C)CC[C@@H]2CC(=O)OCC2(C)C(=C)C1</smiles>

3. DDQ

93

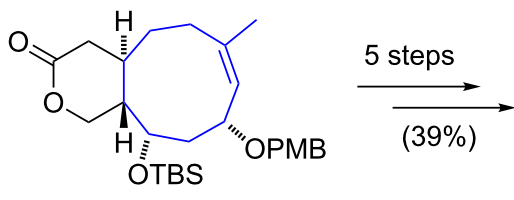

91

4. DMP

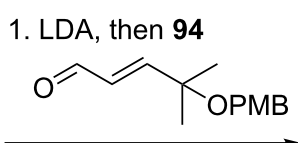

2. $\mathrm{DCC}, \mathrm{CuCl}_{2}$

(26\%)<smiles>C=C1CC(=O)/C=C(/C)CC[C@H]2/C(=C/C=C/C(C)(C)O)C(=O)OC[C@]12C</smiles>

blumiolide C (11) 
ters at the $\mathrm{C} 2$ and $\mathrm{C} 3$ positions (Scheme 10) [54]. The synthesis commenced with the preparation of diol 96 by a palladiumcatalyzed hydrostannylation of 2-butyne-1,4-diol (95). Regioselective silylation with tert-butyldimethylsilyl chloride of the sterically less hindered alcohol, iodination and silylation of the primary alcohol with trimethylsilyl chloride gave vinyl iodide 97. The following palladium-catalyzed B-alkyl Suzuki-Miyaura cross coupling between the borane derived from alkene $\mathbf{9 8}$ and vinyl iodide 97 furnished a $Z$-configured alkene. Deprotection of the trimethylsilyl ether then afforded alcohol 99. A rhodium(II)-catalyzed $\mathrm{O}-\mathrm{H}$ insertion reaction of the rhodium carbenoid derived from diazophosphonoacetate $\mathbf{1 0 0}$ and alcohol
99 afforded intermediate $\mathbf{1 0 1}$ which was treated with lithium diisopropylamide and aldehyde $\mathbf{1 0 2}$ to afford alkene $\mathbf{1 0 3}$ with high $E$-selectivity. The following asymmetric copper(II)catalyzed Claisen rearrangement [55], which is postulated to proceed via the chair-like transition state 104, afforded key intermediate 105 with high diastereo- and enantioselectivity. Preparation of the $\delta$-lactone $\mathbf{1 0 6}$ of the A ring of xeniolide $\mathrm{F}$ was then realized by treatment of Claisen product $\mathbf{1 0 5}$ with the methylene Wittig reagent, followed by desilylation and lactonization. Although a successful synthetic approach leading to lactone $\mathbf{1 0 6}$ was thus established, further efforts to complete the total synthesis of xeniolide F (12) have yet to be reported.<smiles>OCC#CCO</smiles>

95
$\mathrm{Bu}_{3} \mathrm{SnH}$,
$\stackrel{\left(\mathrm{Ph}_{3} \mathrm{P}\right)_{2} \mathrm{PdCl}_{2} \text { (cat.) }}{\longrightarrow}$

$(87 \%)$<smiles>CCCCC(=CCO)CO</smiles>

96

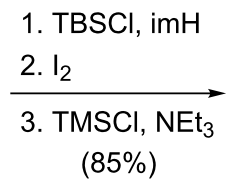

$(85 \%)$<smiles>COCC(I)=CCO[SbH2]</smiles>

97

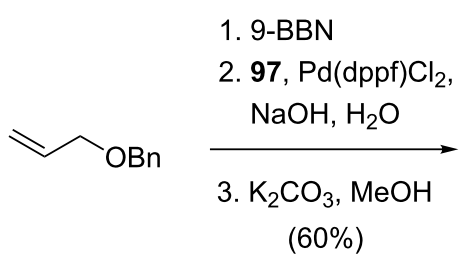

98<smiles>OC/C(=C/CO[SbH3])CCCOCc1ccccc1</smiles>

99

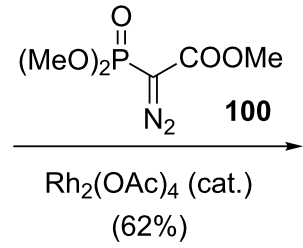

(62\%)<smiles>COC(=O)C(OCC(=CCO[SbH3])CCCOc1ccccc1)[P+](C)=O</smiles>

101

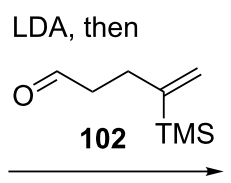

(87\%)

$E / Z=9: 1$

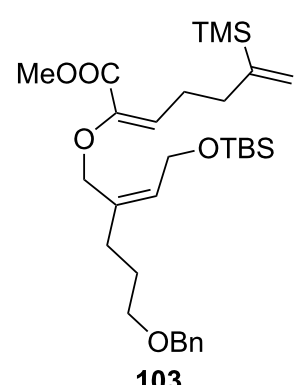

103

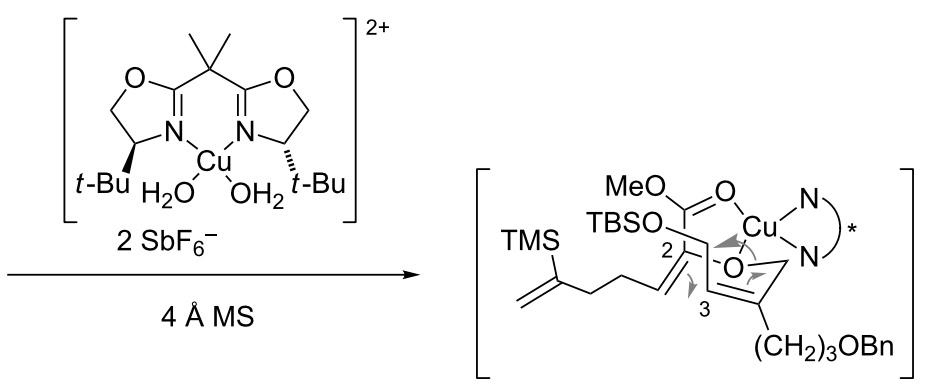

104

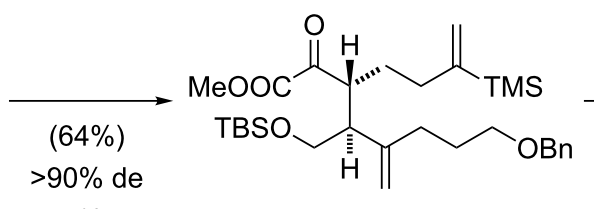

$>99 \%$ ee

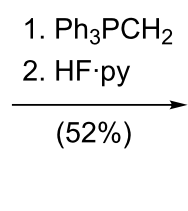<smiles>C=C(C)CC[C@H]1C(=C)C(=O)OC[C@H]1C(=C)CCCOCc1ccccc1</smiles>

106<smiles>C=C1CC[C@@]23CC[C@H](O)[C@@]2(CCC1=C)COC(=O)/C3=C\C=C\C(C)(C)O</smiles>

xeniolide $F(12)$ 
Efforts aimed at constructing the core structure of xenibellol A (15) [15] and umbellacetal (114) [56] employing a 2,3-Wittig-Still rearrangement as the key step were reported by Danishefsky and co-workers (Scheme 11) [57]. In contrast to other xenicanes mentioned above, xenibellol A (15) does not possess the characteristic nine-membered carbocyclic ring but rather features a 6,5,5-ring system, containing an unusual oxolane bridge between $\mathrm{C} 1$ and $\mathrm{C} 7$. Hajos-Parrish diketone (107) [39] served as the starting material for the preparation of key intermediate 112. Selective reduction of the ketone and silylation of the resulting alcohol furnished enone $\mathbf{1 0 8}$. $\alpha$-Carboxylation of the enone with magnesium methyl carbonate and a global reduction of the carbonyl functionalities afforded allylic alcohol 109. The precursor for the key reaction was obtained by formation of the methoxymethyl (MOM) ether from primary alcohol 109 and subsequent conversion of the allylic alcohol to stannane 110. The following 2,3-Wittig-Still rearrangement [58] employing $n$-butyllithium afforded primary alcohol 111 in $31 \%$ yield and enabled the installation of the $\mathrm{C} 1$ quaternary stereocenter. According to the authors, a competing 1,2-Wittig rearrangement and reduction pathway posed a significant challenge in this transformation. Desilylation and regioselective tosylation of the primary alcohol 111 set the stage for the construction of the oxolane via Williamson etherification, which was realized by treatment with potassium hydride. Surprisingly, the following deprotection of the MOM ether using standard reaction conditions ( $1 \mathrm{~N}$ aqueous hydrochloric acid) led to opening of the oxolane ring and afforded tricycle $\mathbf{1 1 3}$ which features the carbon framework of structurally related umbellacetal (114). Gratifyingly, when magnesium bromide and ethanethiol were used as a mild alternative for the cleavage of the MOM ether, the xenibellol core could be obtained. Although the key 2,3-Wittig-Still rearrangement proceeded in low yield and further improvements are necessary, a promising route towards the synthesis of umbellacetal (114) and xenibellol (15) was thus established.

Yao and co-workers have investigated a synthetic approach towards the soft coral metabolite plumisclerin A by Pauson-Khand annulation and $\mathrm{SmI}_{2}$-mediated radical cyclization [59]. The xenicane-related diterpenoid (isolated from the same marine organism as xenicin 116) possesses a complex ring<smiles>CC12CCC(=O)C=C1CCC2=O</smiles>

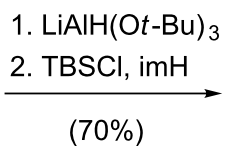

107<smiles>CC1([SeH])CCC2=CC(=O)CCC21C</smiles>

108
1. $(\mathrm{MeO}) \mathrm{Mg}(\mathrm{OC}(\mathrm{O}) \mathrm{OMe})$, $125^{\circ} \mathrm{C}$ 2. $\mathrm{LiAlH}_{4}$ $(47 \%)$ $\mathrm{dr}=7.5: 1$<smiles>[Y16]C1CC[C@@H](O)C(CO)=C1CC[OH+]</smiles>

1. $\mathrm{MOMCl}, \mathrm{DIPEA}$
2. $\mathrm{KH}$, then $\mathrm{Bu}_{3} \mathrm{SnCH}_{2} \mathrm{I}$ $(59 \%)$

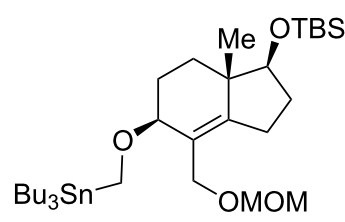

110

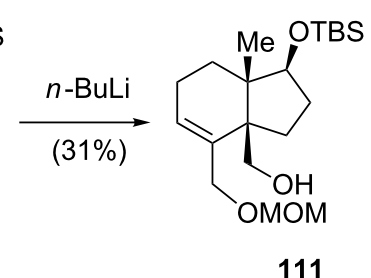

111

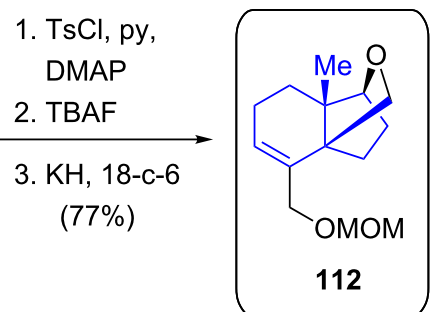

1. $\mathrm{TsCl}, \mathrm{py}$, DMAP 2. TBAF $\mathrm{KH}, 18-\mathrm{c}-6$ $(77 \%)$

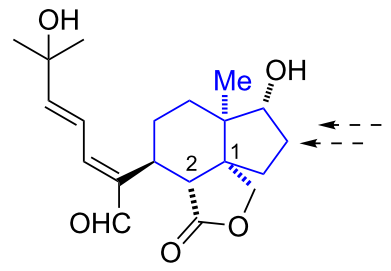

umbellacetal (114)

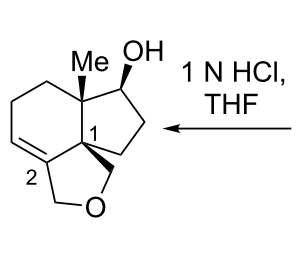

113
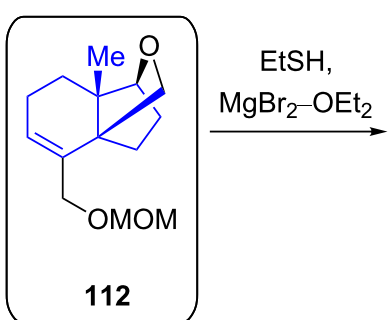

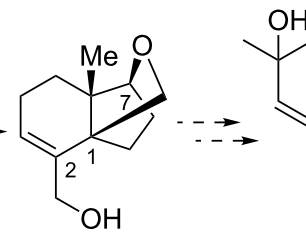

115

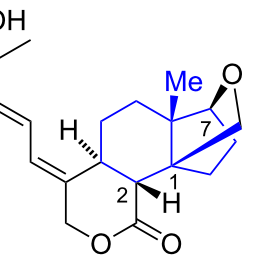

xenibellol A (15) 
system that is proposed to be biosynthetically derived from the xenicin diterpenoid $\mathbf{1 1 6}$ by an intramolecular [2+2] cycloaddition (Scheme 12) [60].

The synthetic route commenced with known aldehyde 119 which was converted to triol $\mathbf{1 2 0}$ in five steps (Scheme 13). The introduction of the benzyl ether next to the alkyne moiety was necessary to control the stereochemical outcome of the key annulation, and further three steps enabled preparation of the annulation precursor 121. The following Pauson-Khand reaction [61] for the construction of the fused bicyclic structure $\mathbf{1 2 2}$ was performed by treatment of $\mathbf{1 2 1}$ with dicobaltoctacarbonyl in the presence of cyclohexylamine. Hydrolysis of the acetonide, chemoselective silylation and oxidation afforded aldehyde $\mathbf{1 2 3}$. Next, the formation of the cyclobutanol ring was realized by an intramolecular samarium diiodide-mediated radical conjugate addition to afford tricycle $\mathbf{1 2 4}$ in $60 \%$ yield. Introduction of the dihydropyran ring of plumisclerin A (118) was envisioned to be carried out at a late stage of the synthesis, but efforts towards its construction have yet to be reported.

In 2009, the enantioselective total synthesis of 4-hydroxydictyolactone (137) was reported by Williams and co-workers (Scheme 14) [62]. Starting from $\alpha, \beta$-unsaturated ester 125, allylic alcohol 126 was synthesized in four steps. Esterification with $(R)-(+)$-citronellic acid (127) yielded a single diastereomer of ester 128. Addition of lithium diisopropylamide to a mixture of 128, trimethylsilyl chloride and triethylamine initiated an Ireland-Claisen rearrangement [63] which gave carboxylic acid 129 in $85 \%$ yield and with high diastereoselectivity $(\mathrm{dr}=94: 6)$. Carboxylic acid $\mathbf{1 2 9}$ was then converted to intermediate $\mathbf{1 3 0}$ in seven further steps. An intramolecular coupling between the formate ester and the allylic bromide provided lactol $\mathbf{1 3 1}$ in excellent stereoselectivity $(\mathrm{dr}>95: 5)$. The preparation of sec-<smiles>CC(=O)O/C=C1\CCC/C(C=O)=C\CC2(C(C)=O)C(C(=O)CCC(C)C)=COC(OC(C)=O)C12</smiles>

116

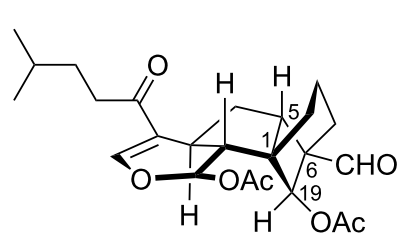

Ox

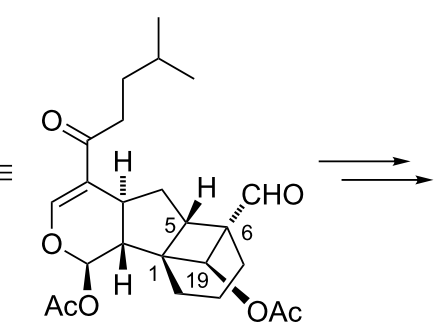

117

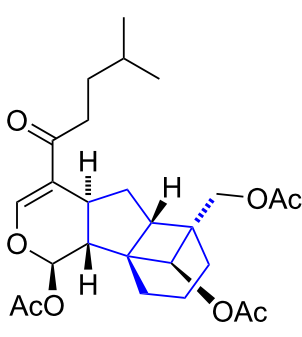

plumisclerin A (118)

Scheme 12: Proposed biosynthesis of plumisclerin A (118)

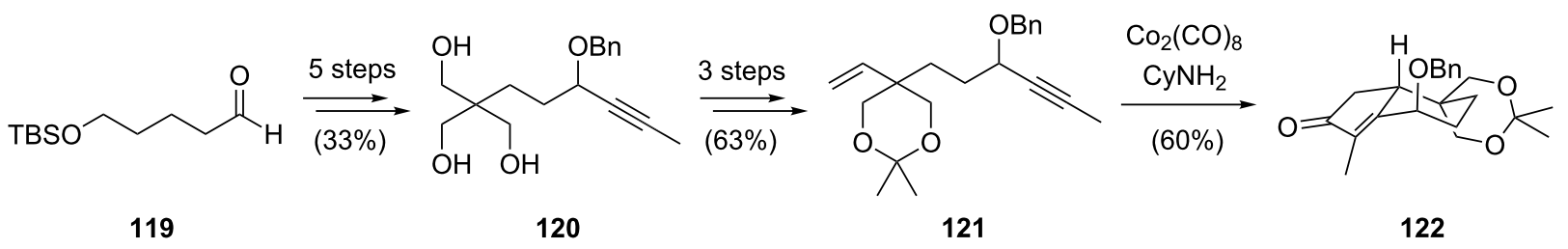

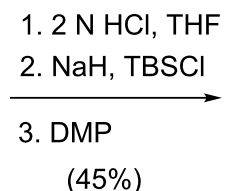

$(45 \%)$

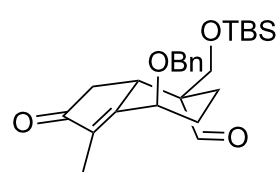

123

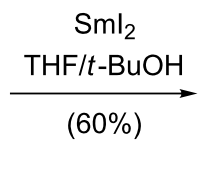

$60 \%)$<smiles>CC1C(=O)CC(Br)(CO[SbH3])C(O)C1COCc1ccccc1</smiles>

$\mathrm{OH}$

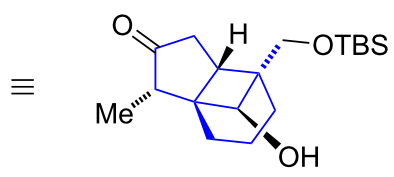

124 


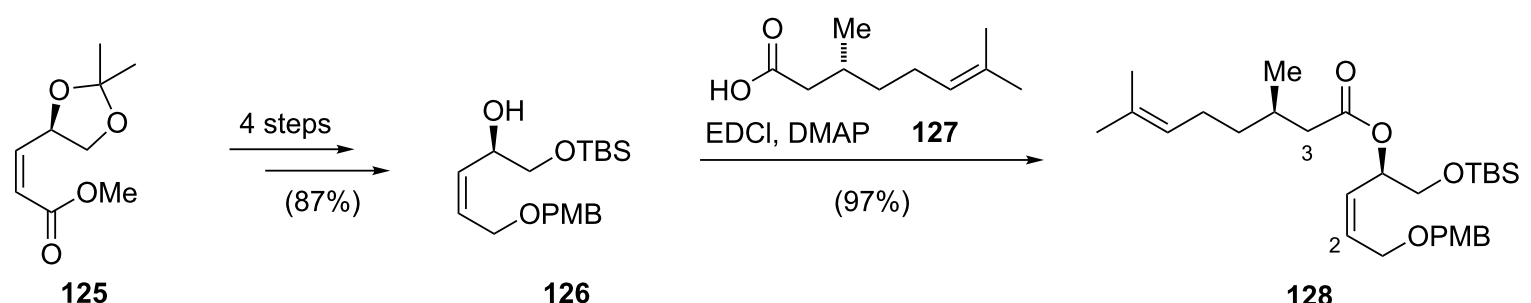

125

126

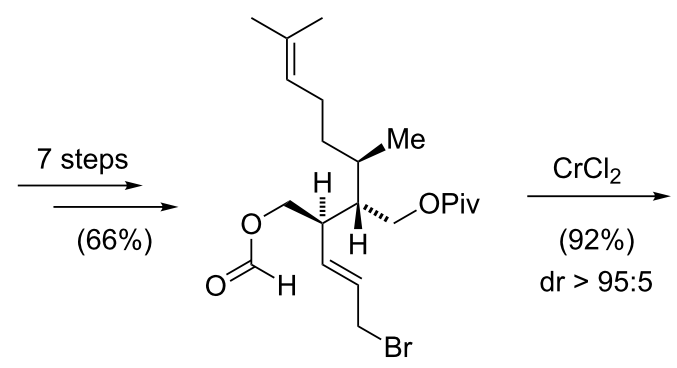

130

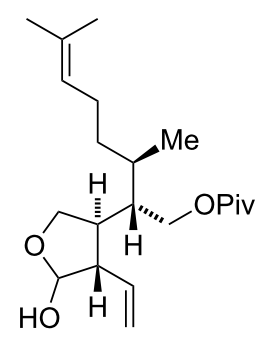

131
129

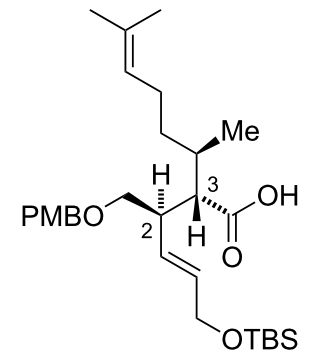

1. TIPSOTf

2. DIBAL

3. TPAP, NMO

4. propargyl bromide, $\mathrm{Mg}, \mathrm{HgCl}_{2}$

$(82 \%)$

TIPSO

133

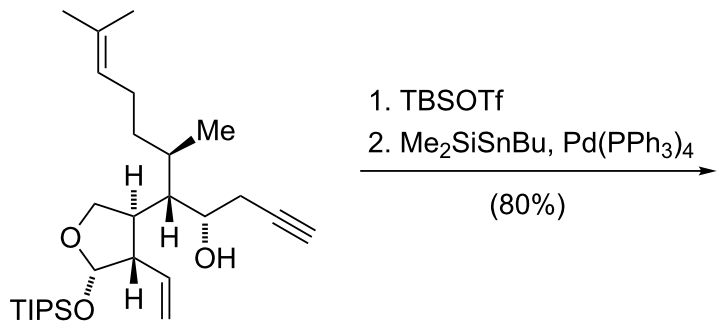

132

1. $\mathrm{I}_{2}$

2. MeLi, Cul

3. NIS

$(75 \%)$

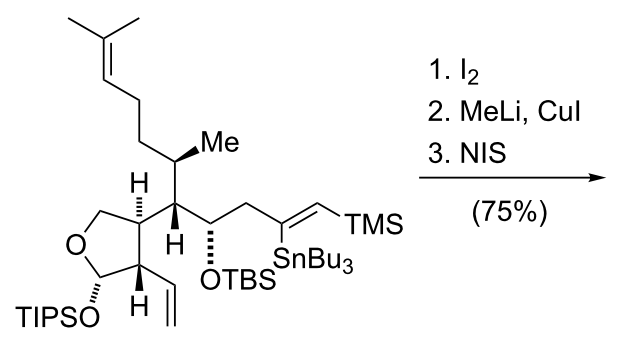

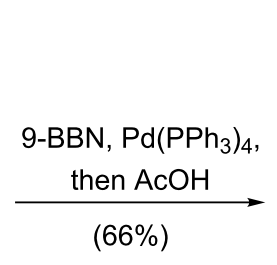

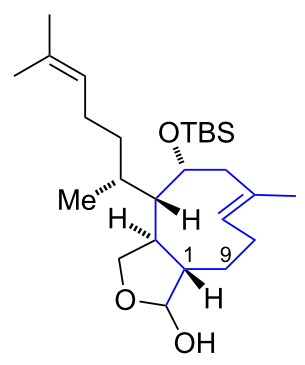

136

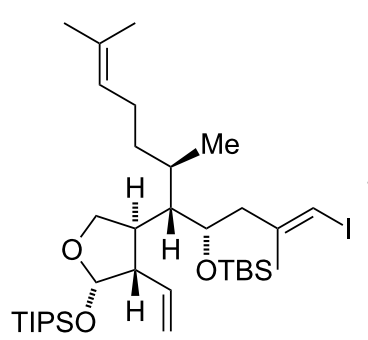

134
1. TBAF

2. PPTS, $\mathrm{MeOH}$

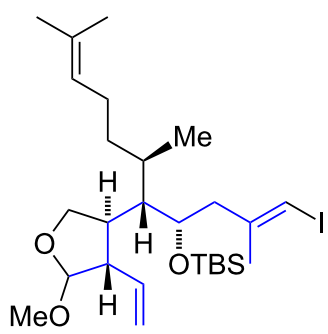

135 
ondary alcohol 132 was accomplished by cleavage of the pivaloate ester, oxidation under Ley-Griffith oxidation [64] and subsequent addition of propargylmagnesium bromide. $O$-Silylation of the propargylic alcohol followed by a regioselective palladium-catalyzed syn-silylstannylation yielded product $\mathbf{1 3 3}$. After employing a three-step protocol for the sequential replacement of the stannyl and silyl substituents, $E$-vinyl iodide 134 was obtained with retention of the olefin geometry. The following intramolecular key coupling step between the vinyl iodide and the terminal alkene for the formation of the nine-membered carbocycle was realized via a B-alkyl Suzuki-Miyaura cross-coupling reaction. Optimization studies of this key ring closure with different protecting groups on the lactol functionality revealed methyl acetal $\mathbf{1 3 5}$ as the most efficient substrate for this transformation. The challenging key step was finally realized in $66 \%$ yield and gave, after hydrolysis of the acetal with acetic acid, a mixture of trans-fused diastereomers 136. Finally, a sequence consisting of oxidation, deprotection of the silyl ether and selenoxide elimination introduced the C1,C9 double bond to furnish 4-hydroxydictyolactone (137). In summary, the total synthesis of 4-hydroxydictyolactone was successfully completed in 30 linear steps with an overall yield of $4.8 \%$.

Paquette and co-workers disclosed the enantioselective total synthesis of the Xenia diterpenoid related crenulatane (+)-acetoxycrenulide (151) [65-67]. The skeleton of crenulatanes, which features an eight-membered carbocyclic ring fused to a cyclopropane ring, may be the product of a photoisomerization of xenicanes. This hypothesis was further supported by the fact that crenulatanes usually co-occur with xenicanes in brown seaweeds of the family Dictyotaceae. Evidence for this proposed biogenetic origin of crenulatanes has been provided by Guella and Pietra who showed that irradiation of 4-hydroxydictyolactone (137) with ultraviolet light $(254 \mathrm{~nm})$ led to the formation of 4-hydroxycrenulide (138) (Scheme 15) [68]. Although this transformation remains mechanistically unclear, the authors suggested that either a free radical process or a photoinduced double bond isomerization $(\mathrm{C} 9, \mathrm{C} 1$ to $\mathrm{C} 1, \mathrm{C} 2)$ followed by an $[1,3] \mathrm{H}$ shift might lead to the formation of 4-hydroxycrenulide (138).

The total synthesis of $(+)$-acetoxycrenulide (151) commenced with preparation of butenolide $\mathbf{1 4 0}$ from $(R)$-citronellol (139) in an 11-step sequence. Next, the two stereocenters at C2 and C3 position were installed by stereoselective conjugate addition of enantiopure $\alpha$-allylphosphonamide 141 to butenolide 140. After cleavage of the chiral auxiliary by ozonolysis, aldehyde $\mathbf{1 4 2}$ was protected as the dimethoxy acetal and reduction of the lactone followed by olefination furnished alkene 143. The lactone fragment of the natural product was then installed by acidic hydrolysis of the acetal functionality and subsequent oxidation gave $\gamma$-lactone 144. Ozonolysis of the terminal alkene and addition of (phenylseleno)methyllithium to the resulting aldehyde afforded secondary alcohol $\mathbf{1 4 5}$. Temporary protection of the alcohol followed by an aldol reaction of the lactone with $E$-crotonaldehyde led to an inseparable mixture $(\mathrm{dr}=1: 1)$ of $\beta$-hydroxy lactone 146. The synthesis of the key precursor for formation of the cyclooctene core was achieved via an acidcatalyzed cyclization to form tetrahydropyran 147 . The following key sequence consisted of a thermal selenoxide 1,2-elimination to generate allyl vinyl ether 148 which underwent a stereoselective Claisen rearrangement [69] to furnish cyclooctenone 149 in 55\% yield. A highly stereoselective Simmons-Smith reaction [70] delivered the cyclopropyl ring exclusively from the accessible $\alpha$-face to give 150. The synthesis of (+)-acetoxycrenulide (151) was completed in seven further steps and in summary proceeded in 33 steps (longest linear sequence) and in $1 \%$ overall yield (Scheme 16).

In addition to the presented strategies for the synthesis of Xenia diterpenoids, total syntheses of the Xenia sesquiterpenes xenitorin $\mathrm{B}$ and $\mathrm{C}$ were also reported [71].

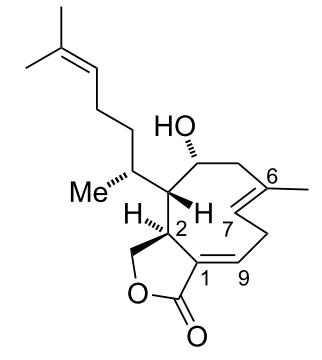

4-hydroxydictyolactone (137)
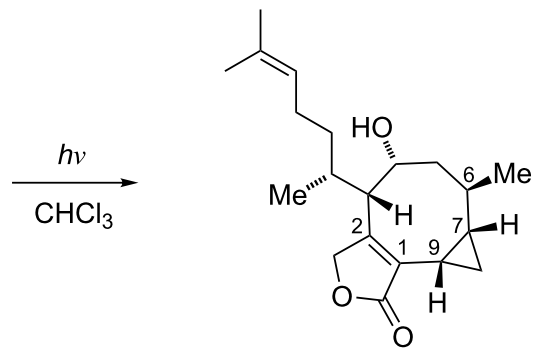

4-hydroxycrenulide (138) 


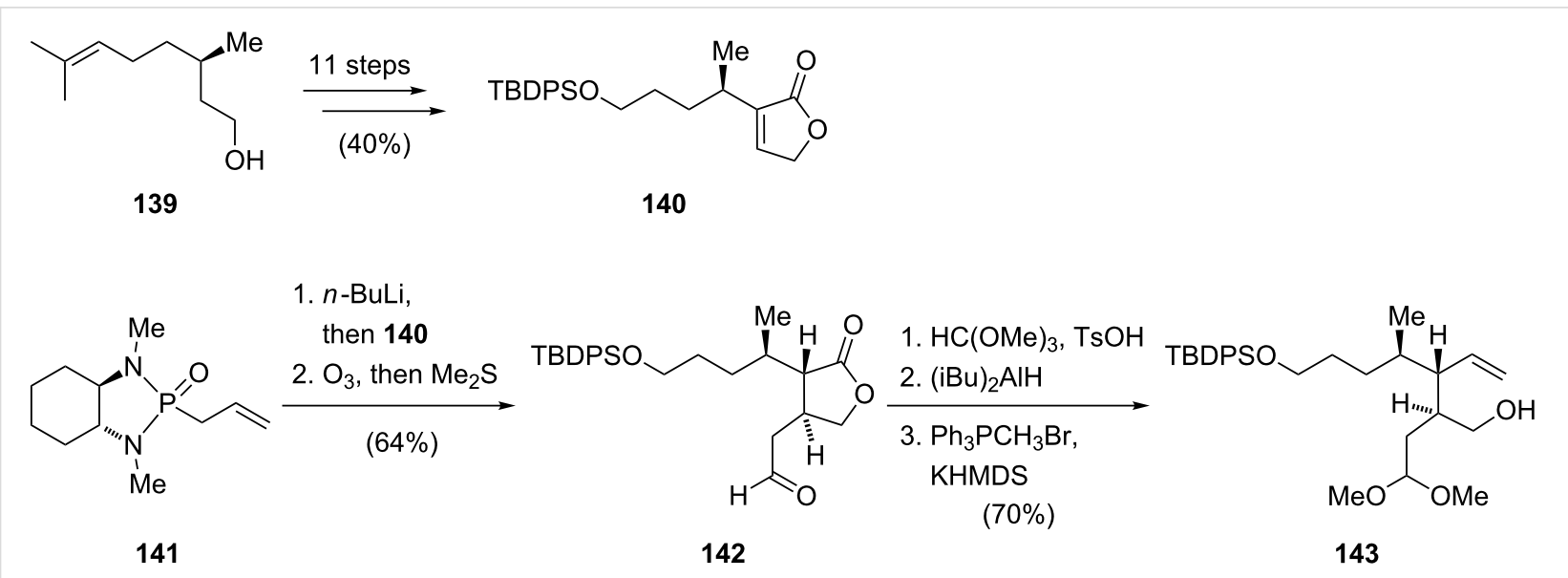

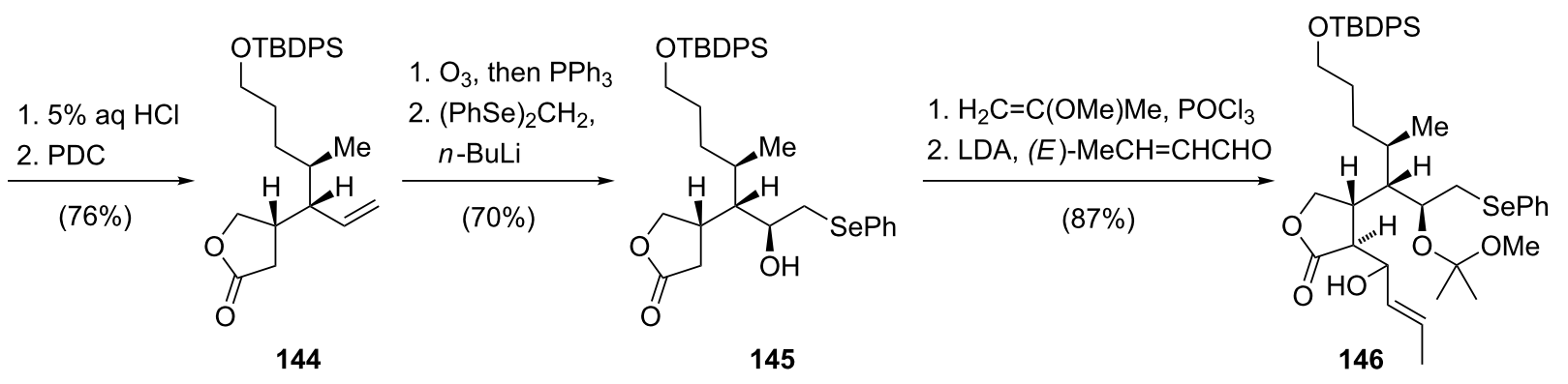

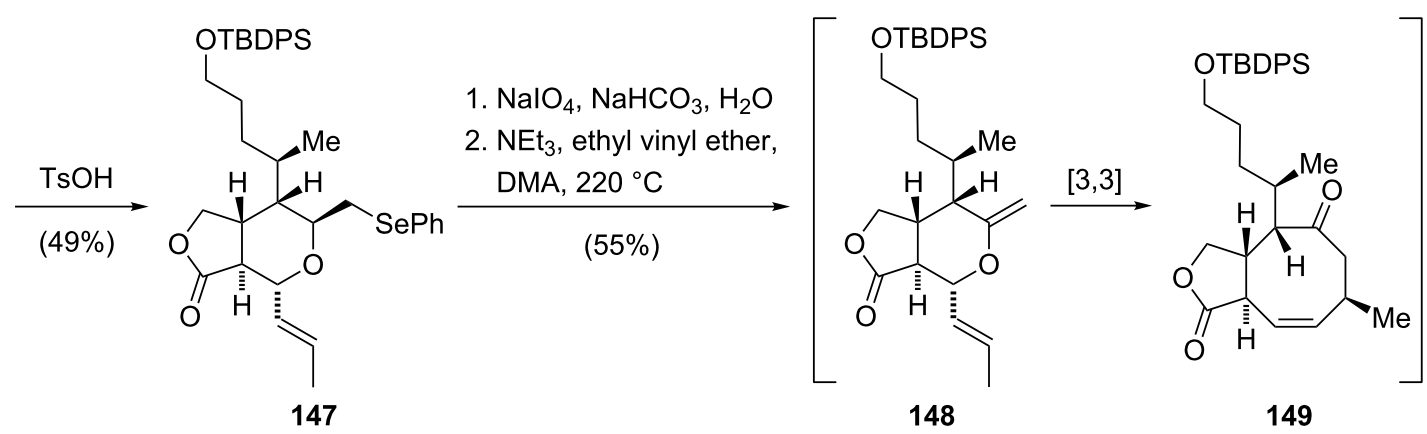

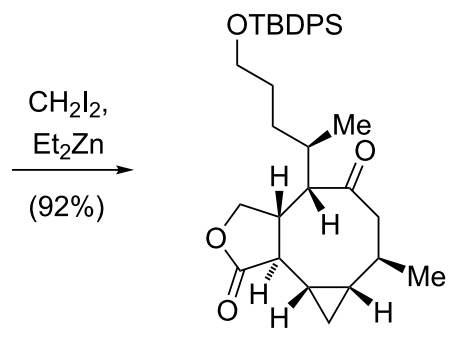

150

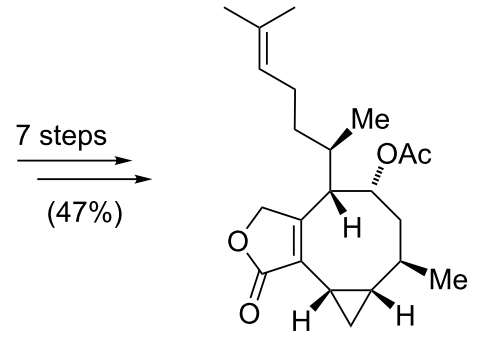

(+)-acetoxycrenulide (151)

Scheme 16: The total synthesis of (+)-acetoxycrenulide (151) by Paquette.

\section{Conclusion}

This review has presented various synthetic approaches towards xenicane and xenicane-related diterpenoids. Additionally, total syntheses of xeniolides and of a crenulatane natural product were illustrated. It has been shown that the rare structural features of Xenia diterpenoids represent an enduring challenge for the total synthesis of these fascinating metabolites. For these reasons, several strategies for the preparation of the characteristic nine-membered carbocyclic ring structures have been developed. The synthetic strategies are typically based on ring 
expansion (Grob-type fragmentation and sigmatropic rearrangements), ring closing (metathesis and transition metal-catalyzed coupling) and ring contracting reactions. The choice of tactic is dependent on the individual substitution pattern of the target compound. However, many of the presented strategies rely on long synthetic sequences that cannot provide large amounts of synthetic material which is required for further investigations of the biological activity of these natural products, and ultimately for drug discovery. The development of short and efficient synthetic routes towards xenicane natural products therefore remains a great challenge of this exciting research field.

\section{Acknowledgements}

We gratefully acknowledge financial support from the FCI (Sachkostenzuschuss to T.M.), the DFG (SFB TRR 152 and Emmy Noether Fellowship to T.M.) and the German National Academic Foundation (Research Fellowship to T.H.). We thank M.Sc. Cedric L. Hugelshofer for helpful discussions during the preparation of the manuscript.

\section{References}

1. Elshamy, A. I.; Nassar, M. I. J. Biol. Act. Prod. Nat. 2015, 5, 78-107. doi:10.1080/22311866.2015.1015611

2. Vanderah, D. J.; Steudler, P. A.; Ciereszko, L. S.; Schmitz, F. J.; Ekstrand, J. D.; van der Helm, D. J. Am. Chem. Soc. 1977, 99, 5780-5784. doi:10.1021/ja00459a040

3. Kashman, Y.; Groweiss, A. Tetrahedron Lett. 1978, 19, 4833-4836. doi:10.1016/S0040-4039(01)85745-2

4. Groweiss, A.; Kashman, Y. Tetrahedron Lett. 1978, 19, 2205-2208. doi:10.1016/S0040-4039(01)86846-5

5. Iwagawa, T.; Amano, Y.; Hase, T.; Shiro, M. Chem. Lett. 1995, 24 , 695-696. doi:10.1246/cl.1995.695

6. Lin, Y.-S.; Eid Fazary, A.; Chen, C.-H.; Kuo, Y.-H.; Shen, Y.-C. Chem. Biodiversity 2011, 8, 1310-1317. doi:10.1002/cbdv.201000173

7. Coval, S. J.; Scheuer, P. J.; Matsumoto, G. K.; Clardy, J. Tetrahedron 1984, 40, 3823-3828. doi:10.1016/S0040-4020(01)88813-X

8. Duh, C.-Y.; El-Gamal, A. A. H.; Chiang, C.-Y.; Chu, C.-J.; Wang, S.-K.; Dai, C.-F. J. Nat. Prod. 2002, 65, 1882-1885. doi:10.1021/np020268z

9. El-Gamal, A. A. H.; Wang, S. K.; Duh, C. Y. J. Nat. Prod. 2006, 69, 338-341. doi:10.1021/np058093r

10. Fattorusso, E.; Romano, A.; Taglialatela-Scafati, O.; Achmad, M. J.; Bavestrello, G.; Cerrano, C. Tetrahedron 2008, 64, 3141-3146. doi:10.1016/j.tet.2008.01.120

11. Almourabit, A.; Ahond, A.; Poupat, C.; Potier, P. J. Nat. Prod. 1990, 53, 894-908. doi:10.1021/np50070a017

12. Schwartz, R. E.; Scheuer, P. J.; Zabel, V.; Watson, W. H. Tetrahedron 1981, 37, 2725-2733. doi:10.1016/S0040-4020(01)92338-5

13. Anta, C.; González, N.; Santafé, G.; Rodríguez, J.; Jiménez, C. J. Nat. Prod. 2002, 65, 766-768. doi:10.1021/np010488x

14. Bishara, A.; Rudi, A.; Goldberg, I.; Benayahu, Y.; Kashman, Y. Tetrahedron 2006, 62, 12092-12097. doi:10.1016/j.tet.2006.09.050

15. El-Gamal, A. A. H.; Wang, S.-K.; Duh, C.-Y. Org. Lett. 2005, 7, 2023-2025. doi:10.1021/ol0505205

16. Miyaoka, H.; Nakano, M.; Iguchi, K.; Yamada, Y. Tetrahedron 1999, 55, 12977-12982. doi:10.1016/S0040-4020(99)00806-6
17. Iwagawa, T.; Nakamura, K.; Hirose, T.; Okamura, H.; Nakatani, M. J. Nat. Prod. 2000, 63, 468-472. doi:10.1021/np990470a

18. Smith III, A. B.; Carroll, P. J.; Kashman, Y.; Green, D. Tetrahedron Lett. 1989, 30, 3363-3364. doi:10.1016/S0040-4039(00)99245-1

19. Miyaoka, H.; Mitome, H.; Nakano, M.; Yamada, Y. Tetrahedron 2000, 56, 7737-7740. doi:10.1016/S0040-4020(00)00689-X

20. El-Gamal, A. A. H.; Chiang, C. Y.; Huang, S. H.; Wang, S. K.; Duh, C. Y. J. Nat. Prod. 2005, 68, 1336-1340. doi:10.1021/np058047r

21. Tkachev, A. V. Chem. Nat. Compd. 1987, 23, 393-412. doi:10.1007/BF00597793

22. Iwagawa, T.; Amano, Y.; Nakatani, M.; Hase, T. Bull. Chem. Soc. Jpn. 1996, 69, 1309-1312. doi:10.1246/bcsj.69.1309

23. Finer, J.; Clardy, J.; Fenical, W.; Minale, L.; Riccio, R.; Battaile, J.; Kirkup, M.; Moore, R. E. J. Org. Chem. 1979, 44, 2044-2047. doi:10.1021/jo01326a040

24. Liu, G.; Smith, T. C.; Pfander, H. Tetrahedron Lett. 1995, 36, 4979-4982. doi:10.1016/0040-4039(95)00938-9

25. Cane, D. E. Acc. Chem. Res. 1985, 18, 220-226. doi:10.1021/ar00115a005

26. Kashman, Y.; Rudi, A. Phytochem. Rev. 2004, 3, 309-323. doi:10.1007/s11101-004-8062-x

27. Prantz, K.; Mulzer, J. Chem. Rev. 2010, 110, 3741-3766. doi:10.1021/cr900386h

28. Miyaura, N.; Suzuki, A. Chem. Rev. 1995, 95, 2457-2483. doi:10.1021/cr00039a007

29. Corey, E. J.; Mitra, R. B.; Uda, H. J. Am. Chem. Soc. 1963, 85, 362-363. doi:10.1021/ja00886a037

30. Corey, E. J.; Mitra, R. B.; Uda, H. J. Am. Chem. Soc. 1964, 86, 485-492. doi:10.1021/ja01057a040

31. Corey, E. J.; Cheng, X.-M. The Logic of Chemical Synthesis; John Wiley \& Sons: New York, 1995.

32. Dieckmann, W.; Kron, A. Ber. Dtsch. Chem. Ges. 1908, 41, 1260-1278. doi:10.1002/cber.190804101236

33. Grob, C. A.; Baumann, W. Helv. Chim. Acta 1955, 38, 594-610. doi:10.1002/hlca.19550380306

34. Ohtsuka, Y.; Niitsuma, S.; Tadokoro, H.; Hayashi, T.; Oishi, T. J. Org. Chem. 1984, 49, 2326-2332. doi:10.1021/jo00187a006

35. Kumar, A.; Singh, A.; Devaprabhakara, D. Tetrahedron Lett. 1976, 17, 2177-2178. doi:10.1016/S0040-4039(00)93151-4

36. Kumar, A.; Devaprabhakara, D. Synthesis 1976, 1976, 461-462. doi:10.1055/s-1976-24082

37. Mc Murry, J. E.; Miller, D. D. Tetrahedron Lett. 1983, 24, 1885-1888. doi:10.1016/S0040-4039(00)81797-9

38. Bertrand, M.; Gras, J.-L. Tetrahedron 1974, 30, 793-796. doi:10.1016/S0040-4020(01)97168-6

39. Hajos, Z. G.; Parrish, D. R. J. Org. Chem. 1974, 39, 1615-1621. doi:10.1021/jo00925a003

40. Renneberg, D.; Pfander, H.; Leumann, C. J. J. Org. Chem. 2000, 65, 9069-9079. doi:10.1021/jo005582h

41. Grieco, P. A.; Clark, J. D.; Jagoe, C. T. J. Am. Chem. Soc. 1991, 113, 5488-5489. doi:10.1021/ja00014a069

42. Tebbe, F. N.; Parshall, G. W.; Reddy, G. S. J. Am. Chem. Soc. 1978, 100, 3611-3613. doi:10.1021/ja00479a061

43. Mushti, C. S.; Kim, J.; Corey, E. J. J. Am. Chem. Soc. 2006, 128, 14050-14052. doi:10.1021/ja066336b

44. Hiroi, K.; Kato, F. Tetrahedron 2001, 57, 1543-1550. doi:10.1016/S0040-4020(00)01111-X

45. Hu, T.; Corey, E. J. Org. Lett. 2002, 4, 2441-2443. doi:10.1021/ol026205p 
46. Larionov, O. V.; Corey, E. J. J. Am. Chem. Soc. 2008, 130, 2954-2955. doi:10.1021/ja8003705

47. Hajos, Z. G.; Parish, D. R. Org. Synth. 1985, 63, 26. doi:10.15227/orgsyn.063.0026

48. Corey, E. J.; Shibata, S.; Bakshi, R. K. J. Org. Chem. 1988, 53, 2861-2863. doi:10.1021/jo00247a044

49. Hamel, C.; Prusov, E. V.; Gertsch, J.; Schweizer, W. B.; Altmann, K. H. Angew. Chem., Int. Ed. 2008, 47, 10081-10085. doi:10.1002/anie.200804004

50. Scholl, M.; Trnka, T. M.; Morgan, J. P.; Grubbs, R. H. Tetrahedron Lett. 1999, 40, 2247-2250. doi:10.1016/S0040-4039(99)00217-8

51. Iversen, T.; Bundle, D. R. J. Chem. Soc., Chem. Commun. 1981, 1240-1241. doi:10.1039/c39810001240

52. Garber, S. B.; Kingsbury, J. S.; Gray, B. L.; Hoveyda, A. H. J. Am. Chem. Soc. 2000, 122, 8168-8179. doi:10.1021/ja001179g

53. Martin, J. C.; Arhart, R. J. J. Am. Chem. Soc. 1971, 93, 4327-4329. doi:10.1021/ja00746a059

54. Pollex, A.; Hiersemann, M. Org. Lett. 2005, 7, 5705-5708. doi:10.1021/ol052462t

55. Abraham, L.; Czerwonka, R.; Hiersemann, M. Angew. Chem., Int. Ed. 2001, 40, 4700-4703. doi:10.1002/1521-3773(20011217)40:24<4700::AID-ANIE4700>3.0.CO ;2-6

56. El-Gamal, A. A. H.; Wang, S.-K.; Duh, C.-Y. Tetrahedron Lett. 2005, 46, 6095-6096. doi:10.1016/j.tetlet.2005.06.168

57. Kim, W. H.; Angeles, A. R.; Lee, J. H.; Danishefsky, S. J. Tetrahedron Lett. 2009, 50, 6440-6441. doi:10.1016/j.tetlet.2009.08.131

58. Still, W. C.; Mitra, A. J. Am. Chem. Soc. 1978, 100, 1927-1928. doi:10.1021/ja00474a049

59. Chen, J.-P.; He, W.; Yang, Z.-Y.; Yao, Z.-J. Org. Lett. 2015, 17, 3379-3381. doi:10.1021/acs.orglett.5b01563

60. Martín, M. J.; Fernández, R.; Francesch, A.; Amade, P.; de Matos-Pita, S. S.; Reyes, F.; Cuevas, C. Org. Lett. 2010, 12 , 912-914. doi:10.1021/ol902802h

61. Khand, I. U.; Knox, G. R.; Pauson, P. L.; Watts, W. E. J. Chem. Soc. D 1971, 1, 36a. doi:10.1039/c2971000036a

62. Williams, D. R.; Walsh, M. J.; Miller, N. A. J. Am. Chem. Soc. 2009, 131, 9038-9045. doi:10.1021/ja902677t

63. Ireland, R. E.; Mueller, R. H. J. Am. Chem. Soc. 1972, 94, 5897-5898. doi:10.1021/ja00771a062

64. Ley, S. V.; Norman, J.; Griffith, W. P.; Marsden, S. P. Synthesis 1994, 1994, 639-666. doi:10.1055/s-1994-25538

65. Wang, T. Z.; Pinard, E.; Paquette, L. A. J. Am. Chem. Soc. 1996, 118, 1309-1318. doi:10.1021/ja9533609

66. He, W.; Pinard, E.; Paquette, L. A. Helv. Chim. Acta 1995, 78, 391-402. doi:10.1002/hlca.19950780210

67. Paquette, L. A.; Wang, T.-Z.; Pinard, E. J. Am. Chem. Soc. 1995, 117, 1455-1456. doi:10.1021/ja00109a041

68. Guella, G.; Pietra, F. J. Chem. Soc., Chem. Commun. 1993, 1539. doi:10.1039/c39930001539

69. Ezquerra, J.; He, W.; Paquette, L. A. Tetrahedron Lett. 1990, 31, 6979-6982. doi:10.1016/S0040-4039(00)97221-6

70. Simmons, H. E.; Smith, R. D. J. Am. Chem. Soc. 1958, 80, 5323-5324. doi:10.1021/ja01552a080

71. Chang, W.-S.; Shia, K.-S.; Liu, H.-J.; Wei Ly, T. Org. Biomol. Chem. 2006, 4, 3751-3753. doi:10.1039/b610427d

\section{License and Terms}

This is an Open Access article under the terms of the Creative Commons Attribution License

(http://creativecommons.org/licenses/by/2.0), which permits unrestricted use, distribution, and reproduction in any medium, provided the original work is properly cited.

The license is subject to the Beilstein Journal of Organic Chemistry terms and conditions:

(http://www.beilstein-journals.org/bjoc)

The definitive version of this article is the electronic one which can be found at:

doi:10.3762/bjoc. 11.273 